2017-09

\title{
Wavelet-based variability of Yellow River discharge at 500-, 100-, and 50-year timescales
}

Su, L

http://hdl.handle.net/10026.1/17705

10.1016/j.gr.2017.05.013

Gondwana Research

Elsevier BV

All content in PEARL is protected by copyright law. Author manuscripts are made available in accordance with publisher policies. Please cite only the published version using the details provided on the item record or document. In the absence of an open licence (e.g. Creative Commons), permissions for further reuse of content should be sought from the publisher or author. 


\section{Wavelet-based variability of Yellow River discharge at 500-, \\ 2 \\ 100-, and 50-year timescales}

3

$4 \quad{ }^{1}$ State Key Laboratory of Earth Surface Processes and Resource Ecology, College of Global

5 Change and Earth System Science, Beijing Normal University, Beijing 100875, P.R.China

$6{ }^{2}$ School of Engineering, The University of Edinburgh, The King's Buildings, Edinburgh EH9 3JL,

7 U.K.

8

9

10

11

12

13

14

15

16

17

18

\author{
$\mathrm{Lu} \mathrm{Su}^{1}$, Chiyuan Miao ${ }^{1 *}$, Alistair G.L. Borthwick ${ }^{2}$, Qingyun Duan ${ }^{1}$
}

* Corresponding authors. Tel.: +86-10-58804191; fax: +86-10-58804191.

E-mail address: miaocy@vip.sina.com (C. Miao)

Highlights for reviews [a maximum of 85 characters, including spaces, per highlight]

(1) Spatial and temporal variabilities of streamflow in the YR are investigated.

(2) Periodic changes of the streamflow are identified at 500-, 100-, and 50-year timescales.

(3) Periodicities are continuous at spatial scale and short timescales.

(4) Strong connection with the Niño 3.4, the AO, and sunspots. 
Abstract: Water scarcity in the Yellow River, China, has become increasingly severe over the past half century. In this paper, wavelet transform analysis was used to detect the variability of natural, observed, and reconstructed streamflow in the Yellow River at 500-, 100-, and 50-year timescales. The periodicity of the streamflow series and the co-varying relationships between streamflow and atmospheric circulation indices / sunspot number were assessed by means of continuous wavelet transform (CWT) and wavelet coherence transform (WTC) analyses. The CWT results showed intermittent oscillations in streamflow with increasing periodicities of 1-6 years at all timescales. Significant multidecadal and century-scale periodicities were identified in the 500-year streamflow series. The WTC results showed intermittent interannual covariance of streamflow with atmospheric circulation indices and sunspots. At the 50-year timescale, there were significant decadal oscillations between streamflow and the Arctic Oscillation (AO) and the Pacific Decadal Oscillation (PDO), and bidecadal oscillations with the PDO. At the 100-year timescale, there were significant decadal oscillations between streamflow and Niño 3.4, the AO, and sunspots. At the 500-year timescale, streamflow in the middle reaches of the Yellow River showed prominent covariance with the $\mathrm{AO}$ with an approximately 32 -year periodicity, and with sunspots with an approximately 80-year periodicity. Atmospheric circulation indices modulate streamflow by affecting temperature and precipitation. Sunspots impact streamflow variability by influencing atmospheric circulation, resulting in abundant precipitation. In general, for both the CWT and the WTC results, the periodicities were spatially continuous, with a few gradual changes from upstream to downstream resulting from the varied topography and runoff. At the temporal scale, the periodicities were generally continuous over short timescales and discontinuous over longer timescales.

Keywords: Yellow River; streamflow; periodicity; wavelet transform

\section{Introduction}

Water is essential for the survival of all organisms, including human beings (Oki and Kanae, 2006). Water availability is vital for human health, economic activity, ecosystem function, and geophysical processes (Milly et al., 2005). Nevertheless, during the past five decades, water scarcity has begun to accelerate across the world. It is estimated that by 2025 as many as 5 billion 
people $-60 \%$ of the 8 billion world population - will be living in countries suffering from water stress (Arnell, 1999). Therefore, the changing characteristics and optimal management of water resources have received great attention in recent decades.

From a resource perspective, runoff is an important component of the hydrological cycle and can be used as a measure of sustainable water availability (Milly et al., 2005). The temporal distribution of global runoff is extremely non-uniform, exacerbating the severe challenge posed by shrinking water resources. Substantial research effort has therefore been focused on streamflow and its fluctuations, including streamflow circulation, river flow oscillations, discharge predictions, etc. (Miao and Ni, 2009).

For a better understanding of fluctuations in streamflow, one can perform a decomposition of the runoff time series into time-frequency space to determine the dominant modes of variability and how such modes vary with time (Torrence and Compo, 1998). Time series in the geosciences generally show sporadic periodicities which are often caused by intermittent climatic oscillations. Most traditional mathematical methods that examine periodicities in the frequency domain, such as Fourier analysis, implicitly assume that the underlying processes are stationary in time (Grinsted et al. 2004), which is not the case in reality for most geo-scientific time series. Windowed Fourier transforms can be used but are limited by the arbitrary fixed length of the window (Torrence and Compo,1998), and there is a tradeoff between temporal and spatial resolution because of Heisenberg's uncertainty principle. Wavelet analysis, however, has an advantage over the more classic techniques because it is not restricted by an assumption of stationarity (Cazelles et al., 2008). Wavelet analysis is a scale-independent, robust approach for decomposing time series into finer scales and is able to identify localized, scattered periodicities (Coulibaly and Burn, 2005).

Wavelet analysis has been widely applied in hydrology since the 1980s (Kumar and Foufoula-Georgiou, 1997). Labat et al. (2004) used a statistical wavelet-based method to reconstruct the monthly discharges of the world's largest rivers. They showed that there was a long dry period in global runoff between 1900 and 1940, followed by a succession of alternating 15-year-long dry and humid periods. This reconstruction displayed more pronounced amplitudes in the dry and humid periods compared with previous estimates. Labat (2008) further analyzed the changes in discharge of 55 large rivers globally using a Morlet continuous wavelet-based analysis, 
and demonstrated that large-river runoff exhibits El-Niño/Southern Oscillation (ENSO)-related and North Atlantic Oscillation (NAO)-related interannual variability, decadal variability, and multidecadal 40-50-year fluctuations. Smith et al. (1998) applied wavelet spectral analyses to the daily discharge records for 91 rivers in five different climate regions across the U.S., and found that the spectral curves were very similar within a region but differed between regions. Labat et al. (2000) applied the continuous Morlet wavelet transform and a multi-resolution orthogonal analysis to rainfall rates and runoffs for karst springs at two locations in France, with the data sampled at different rates. The results showed that both rainfall rate and karst spring runoff were characterized by highly non-stationary and scale-dependent behavior. Runoff was influenced by the large nonlinearities in the karstic system and by the time structure of the rainfall rates. Gaucherel (2002) exploited the benefits of the continuous wavelet transform (CWT) to detect new periodicities in the flow curves for basins in French Guiana. Their results showed that the so-called 'short March summer' (a temporary reduction in rain over the Guiana Shield during the rainy season) was due to the influence of the Atlantic Ocean on the continent. Nourani et al. (2013) used a wavelet transform to identify dynamic, multi-scale features in the runoff time series and to remove noise. The results showed that the application of the wavelet transform increased the performance of the feed-forward neural network (FFNN) rainfall-runoff models in predicting runoff peak values. Nalley et al. (2013) adopted the discrete wavelet transform (DWT) technique to detect trends in the mean surface air temperature over southern regions of Ontario and Quebec, Canada, for the period 1967 - 2006. They found that high-frequency components ranging from 2 to 12 months were more prominent in the higher resolution data. Pathak et al. (2016) used DWT to analyze variability in seasonal temperature, precipitation, and streamflow in the Midwestern United States. The results indicated an upward trend in temperature, with different periodicities being effective for detecting trends in different seasons and different hydrological components. Yarleque et al. (2016) adopted a high-resolution spatiotemporal wavelet reconstruction method to assess the spatial variability in precipitation over complex mountain terrain at multiple spatiotemporal scales; the validation study demonstrated the good overall performance of the wavelet method. CWT and wavelet transform coherence (WTC) analyses were applied by Niu and Chen (2016) to the hydrological time series (runoff, soil moisture, and evapotranspiration) for the ten sub-basins that make up the Pearl River basin in South China for the period $1952-2000$. They 
found that runoff had greatest correlation with precipitation variability and least with evapotranspiration, and that the attenuation of runoff in response to precipitation variability occurred mainly within a timescale of two years.

One-dimensional CWT focuses only on a single variable (e.g. streamflow). Water discharge is an essential part of any sensible hydrological system, and is also strongly associated with internal climate feedback mechanisms (Miao et al., 2016), such as the known atmospheric circulation modes, and external forcings, such as solar activity (Hao et al., 2008). Knowledge of the spatially and temporally non-stationary behavior of streamflow is vital for a better understanding of the complicated hydrology-climate relationship and the dynamics of the hydrological cycle (Coulibaly and Burn, 2005), which in turn will assist with accurate prediction of water runoff.

To achieve this objective, two-dimensional wavelet transforms have been widely used [e.g. the cross wavelet transform (XWT) and wavelet transform coherence (WTC)]. The two-dimensional approach has the advantage of being able to detect transient associations between the studied non-stationary signals in both the time and frequency domains simultaneously (Yu et al., 2015). Calculated from two CWTs, the XWT exposes regions with high common power and further reveals information about the phase relationship. The WTC is also calculated from two CWTs and can quantify the degree of linear relationship between two series (e.g. precipitation and ENSO) in both the time and frequency domains. XWT reveals high common power; WTC finds locally phase-locked behavior.

Labat (2010) used XWT to study the relationship between annual continental freshwater discharge and five climate indices over the period 1876 - 1994. The study revealed temporal correlations between discharge and indices for five continents, sometimes over the entire time interval but more often over restricted intervals. Coulibaly and Burn (2005) used XWT to gain insights into the dynamic relationship between seasonal streamflow and the dominant modes of climate variability in the Northern Hemisphere: the wavelet cross-spectra revealed strong climatestreamflow covariance in the 2-6-year period after 1950, regardless of climatic index or season. Briciu and Mihăilă (2014) used WTC to study the influence of climatic oscillations and sunspot number on river flows in Romania, Ukraine, and Moldova. The WTC analysis showed that there was an approximately 11-year periodicity between sunspots and river flow, which indicates the 
constant influence of solar activity on climatic oscillations and rivers. Gobena and Gan (2009) used WTC to identify links between primary Pacific climate variability modes and low-frequency hydroclimatic variability in the South Saskatchewan River basin in Canada. At the interannual scale, Gobena and Gan observed strong coherency but inconsistent phase differences between streamflow and the Niño 3 index, the Pacific-North America pattern (PNA), and the Pacific Decadal Oscillation (PDO). At the interdecadal scale, the PDO and streamflow exhibited consistently strong coherence with a stable phase difference of $180^{\circ}$ at scales greater than 20 years. Nalley et al. (2016) applied WTC to analyze the relationships between streamflow data collected from the southern regions of Quebec and Ontario over 55 years and the ENSO, the PDO, and the Arctic Oscillation (AO). WTC analyses showed that the inter-annual influence of the ENSO and the NAO occurred at $2-6$ year periodicities, and that the influence of the PDO occurred at periodicities up to 8 years and exceeding 16 years. Keener et al. (2010) used both XWT and WTC to identify and quantify the significance of a teleconnection between sea surface temperatures (SST) associated with the Niño 3.4 index and streamflow in the Little River watershed in Georgia, USA. The strongest 3-7 year shared power was observed between SST and streamflow data, whereas the strongest co-variance was observed between $\mathrm{SST}$ and $\mathrm{NO}_{3}$ load data. Wang et al. (2013) used XWT and WTC to assess the possible relationships between monthly extreme headwater flow in the Tarim River basin, climatic indices, and regional climate. The results showed that different circulation indices may influence the trends in hydrological extremes Conservancy Commission (YRCC), 2012). Northern China has heavy socio-economic dependence on the Yellow River, with about 110 million inhabitants occupying its basin in 2000 (Miao and Ni, in different rivers. Tamaddun et al. (2016) used XWT and WTC to analyze the interaction between streamflow in the western United States and climate indices over the period $1951-2010$. The results showed that changes in streamflows were coincident with both the ENSO and the PDO, but in different time-scale bands and at various time intervals. The ENSO was strongly correlated with streamflow in the $10-12$ years band whereas the PDO was strongly correlated with streamflow in the $8-10$ years and $>16$ years bands.

The Yellow River (or Huanghe) is the sixth longest river in the world (Yellow River 2009). For the past half century, the Yellow River has been suffering from water shortages, with the situation compounded by the ever-growing population and flourishing economy (Miao et al., 
2011; Wu et al., 2017). Since the 1950s, discharge from the Yellow River to the Bohai Sea has steadily decreased owing to decreased precipitation and increased human activities, and is currently at only $20 \%$ of the pre-1950s discharge levels (Yang and Sun, 1998; Xu et al., 2010). Equally striking is the number of days in recent decades that the lower reaches of the Yellow River suffered from no-flow or low-flow conditions, whose occurrences rose from fewer than 20 days per year in the 1950s to an astounding 226 days per year in the 1990s (Xu, 2004). Thanks to the Xiaolangdi Dam, which became operational in 1999, there have been zero no-flow days in the lower Yellow River since 2000. The severity of the previous events highlights the importance of optimal management of water resources in the Yellow River basin.

Many researchers have applied wavelet analysis to the study of oscillations in streamflow in the Yellow River. Hao et al. (2008) analyzed long-term precipitation series $(1736-2000)$ for the middle and lower reaches of the Yellow River and its four sub-regions, and found that the precipitation had interannual and interdecadal oscillations of $2-4$ years, quasi-22 years, and $70-80$ years. Sun (2010) used the XWT method to analyze the runoff characteristics and multi-timescale correlations between runoff and climate indices in the Yellow River source region. The results showed that runoff in the source region had interannual and interdecadal periodic variations and the coherence between runoff and climate indices varied seasonally. The relationship between SST and discharge at the Lijin gauging station from 1950 to 2008 was analyzed by XWT and squared wavelet coherence by Liu et al. (2011), who found the most significant common power occurred at the 2-8-year timescale. Zhang et al. (2012) used both XWT and WTC to describe and identify the climate and river discharge features in the Yellow River source region, and demonstrated that the first instance of zero river discharge (in 1961) related solely to precipitation, whereas the remaining instances resulted from a combination of air temperature and precipitation. He et al. (2013) applied CWT to detect the characteristics of variation in natural and observed streamflow series from six hydrologic gauging stations in the Yellow River from 1956 to 2007. The results showed that streamflow at all stations other than the Guide station had the strongest periodicity at 19 - 21 years on a 52-year timescale. Huang et al. (2015) explored the correlations between ENSO events and Nonparametric Multivariate Standardized Drought Index (NMSDI) variations from 1953 to 2012 in the Yellow River basin using XWT. The results showed that ENSO events exhibited a statistically significant negative correlation with NMSDI variations, suggesting that 
these variations have a strong impact on the evolution of drought. Wang and Sun (2016) used CWT to analyze the multi-timescale characteristics and coupling between runoff and sediment in Lower Yellow River over the period 1950 - 2005. They found that the main periods of runoff were essentially consistent with the main periods of sediment discharge. Wei et al. (2016) applied wavelet transforms to detect periodic variations in streamflow and suspended sediment discharge at eight hydrological stations along the mainstream of the Yellow River between 1950 and 2013, and found many oscillation cycles resulting in alternating wet/dry and high/low sediment-discharge periods.

Existing research has mostly focused on individual streamflow (e.g. Yang et al., 1998; Lan, 2001; Miao and Ni, 2009; He et al., 2013). Water discharge is highly associated with known atmospheric circulation modes and external forcing such as solar activity; so it is also necessary to analyze the co-varying relationships between streamflow and climatic indices such as Niño 3.4, the AO, the PDO, and sunspots. Wavelet analysis can be used to investigate the coherence between streamflow and climatic variables, as well as individual streamflow periodicities. More importantly, previous studies of the Yellow River mainly dealt with streamflow series from different hydrological stations separately (e.g. Lan et al, 2001; Yang et al., 2004; Miao et al., 2010) and rarely focused on comparison and analysis of results across different spatial regions. A comprehensive analysis of the spatial characteristics of streamflow is essential for overall management of water resources across the entire Yellow River basin. Furthermore, previous research on the Yellow River has tended to concentrate on data from the last half century (e.g. Liu et al., 2011; Milliman et al., 2008; Huang et al., 2015). Longer time series are of vital significance for periodicity analyses because they contain richer information, enabling a more effective analysis.

There is no doubt that periodicity analyses depend heavily on the accuracy of the data used. Instrumental records of the Yellow River streamflow prior to the 20th Century do not exist and the implementation of instrumental records did not become popular in the region until the 1950s. Therefore, instrumental records can reflect only a fraction of variability for this regions. However, to understand better the dynamic distribution and evolution of streamflow patterns in the Yellow River, it is essential to assess the relationships between the streamflow and climatic variations on a long time scale (Liu et al., 2010). To solve this dilemma, hydro-meteorological reconstruction has 
been utilized effectively in many areas of the world (Littell et al., 2016; Lough et al., 2015; Zhang et al., 2015; Liu et al., 2010; Shiau et al., 2007; Gedalof et al., 2004; Brito-Castillo et al., 2003; Woodhouse, 2001; Hidalgo et al., 2000; Wang et al., 1999). Many kinds of reconstruction methods have been applied in hydro-meteorology. For example, tree ring width has been successfully applied to reconstruct high-resolution hydrological data (e.g. precipitation and runoff) worldwide (Littell et al., 2016; Sun et al., 2013; Liu et al., 2010; Gou et al., 2010; Qin et al., 2004; Woodhouse, 2001; Li and Yuan,1997); coral fluorescence has been used to reconstruct river mouth runoff and nearshore rainfall globally (Lough et al., 2015; Grove et al., 2013; Isdale et al.,1998; Isdale,1984); annually laminated stalagmites have been used to reconstruct precipitation, runoff, and flood events (González-Lemos et al., 2015; Xu, 2015a; Xu, 2015b; Tan et al., 2014; Yadava and Ramesh, 2005); information from gazetteers and corresponding historical documents has also been widely used for reconstructing proxy indicator series (Zhang et al., 2015; Xiao et al., 2015; Ye and Fang, 2014; Fang et al., 2012). Abundant hydrological descriptions from a large number of historical documents are available for the Yellow River dating back hundreds of years (Zhang et al., 2015), providing researchers the opportunity to reconstruct the Yellow River runoff.

In this paper, we use CWT to assess the periodicity of streamflow in the Yellow River, including natural streamflow, observed streamflow, and reconstructed streamflow, over three different timescales, ranging from roughly half a century to almost five centuries. Additionally, we use wavelet coherence analysis to test for co-varying relationships between streamflow and atmospheric circulation indices (Niño 3.4, AO, PDO), and between streamflow and sunspots. The paper is organized as follows. First, we describe the study area and the data. Second, we describe the methods used, including the CWT and the WTC. Third, we present the results and a discussion of the wavelet analysis. Finally, we discuss our conclusions.

\section{Study area and data}

\subsection{Study area}

The Yellow River is located at $96^{\circ} \mathrm{E}-119^{\circ} \mathrm{E}$ longitude and $32^{\circ} \mathrm{N}-42^{\circ} \mathrm{N}$ latitude (Miao et al., 2010) and originates in the Bayan Har mountains of the Qinghai-Tibet Plateau in western China (as shown in figure 1). Before emptying into the Pacific Ocean near the city of Dongying in Shandong province, the Yellow River flows through nine provinces. It meanders for $5464 \mathrm{~km}$ and 
covers a drainage basin of $795,000 \mathrm{~km}^{2}$ (YRCC, 2012). The Yellow River basin is commonly divided into three reaches according to its physical characteristics. The upper reaches begin at the river source and end at Hekou, have a total length of $3472 \mathrm{~km}$, and comprise $51.4 \%$ of the total drainage area. The middle reaches are located between Hekou and Huayuankou, are $1206 \mathrm{~km}$ long, and comprise $45.7 \%$ of the total drainage area. The lower reaches run from Huayuankou to the river mouth, covering a distance of $786 \mathrm{~km}$, and comprise merely $2.9 \%$ of the total basin area.

\section{Figure 1}

\subsection{Data}

\subsubsection{Observed streamflow}

Observed hydrological series from the seven gauging stations listed in Table 1 were used to analyze changes in streamflow characteristics. The streamflow series are of different lengths because the stations used for hydrological monitoring of the Yellow River have changed over time. We used streamflow series for 1956 - 2015 from five stations (Tangnaihai, Lanzhou, Hekou, Huayuankou, and Lijin) to analyze interannual periodicity at the 50-year timescale. To analyze interannual periodicity at the centennial scale, we selected streamflow series for $1919-2015$ from two stations (Longmen and Sanmenxia).

\subsubsection{Natural streamflow}

Natural hydrological series of the same length as the observed streamflow series were also used to analyze changes in streamflow characteristics. We used streamflow series for $1956-2015$ from five stations (Tangnaihai, Lanzhou, Hekou, Huayuankou and Lijin) to analyze interannual periodicity at the 50-year timescale. To analyze interannual periodicity at the centennial scale, we selected streamflow series for 1919 - 2015 from two stations (Longmen and Sanmenxia).

Natural streamflow is constituted from observed runoff that is measured by hydrological stations at river sections and additional runoff driven by human activities. In this study, natural streamflow was calculated by the YRCC according to the principle of water balance. The calculation procedure is shown below (Li, et al., 2001):

$$
W_{n a}=W_{o b}+W_{a g+i n}+W_{r e}
$$


where $W_{n a}$ is natural streamflow; $W_{o b}$ is observed streamflow; $W_{a g+i n}$ is the total water consumed by agricultural irrigation, industry, and urban living; and $W_{r e}$ is the variation in water stored in the large and medium-sized reservoirs above the river section.

\subsubsection{Reconstructed streamflow}

On the basis of historical documents of Yellow River flooding in the Qing dynasty, the distribution of droughts and flooding in China during the last 500 years (CMA,1981), and other historical data, Wang et al. (1999) used the following six methods to reconstruct the annual discharge series at Sanmenxia station covering the period from 1470 to 1918. (1) The correlation between discharge at Qingtongxia and Shanxian (former name for Sanmenxia) stations was calculated, with the surface level record in Wanjintan benchland (located in Sanmenxia) as a parameter. This method was used only for years when the rising water level was available in both Qingtongxia and Wanjintan. (2) The second method is based on the same correlations as in method (1) but with the drought and flood grades in the Hekou - Sanmenxia basin as a parameter. This method was used for years when the rising water level was available only in Qingtongxia. (3) The coaxial correlation method. A five-variable coaxial correlation diagram was established based on the height of rising water level, the months of peak flood, the times of flooding, the drought and flood grades in the Hekou - Sanmenxia basin, and the reconstructed annual runoff. Reconstructed annual runoff in Sanmenxia could be obtained given the other four variables, which are available from the historical records. This method was used in years when the rising water level was available in Wanjintan. (4) High/low flow ranking method. Reconstructed annual runoff in Sanmenxia was calculated according to the relationship with average precipitation above Sanmenxia station. This method was used in years when the level of water rising was lower in Wanjintan or when there was a lack of data (during the period $1864-1900)$. (5) Charts of dryness/wetness. Reconstructed annual runoff in Sanmenxia was calculated on the basis of the distribution of droughts and floods in China over the past 500 years (CMA, 1981). This method was adopted for 1470 - 1918 when information was unavailable for Qingtongxia and Wanjintan. (6) Analysis of historical documents analysis method. Reconstructed annual runoff in Sanmenxia was deduced according to the historical records for precipitation and floods, and was used only for the years when catastrophic floods occurred (Wang et al., 1999). 
When several methods could be used, the results were evaluated and the most appropriate value chosen. In a comprehensive analysis, Wang (1999) observed the following principles: (1) select data with the highest consistency; (2) choose data with no missing high/low flow years; (3) match the records with those at Qingtongxia, which lies upstream; (4) analyze long-term high/low flow periods using different approaches. In general, the methods that used correlations between Qingtongxia and Shanxian stations (methods 1 and 2, above) were found to be the most reliable because of the high correlation between the rising water level and natural annual runoff at Qingtongxia (correlation coefficient $r=0.931$ ). The coaxial correlation method, the high/low flow ranking method, and the analysis of historical documents were also deemed reliable because of the abundance of available historical information.

The YRCC extended Wang et al. (1999)'s work and reconstructed the annual streamflow time series at Sanmenxia station for the period 1919 - 2015 using the same methods as for observational gauge records. Studies on long term periodicities often rely on reconstructed data dating back hundreds of years, despite the fact that it is difficult to validate the precision of the reconstructed data because of the lack of early observations. Although there are differences between the observed and reconstructed hydro-meteorological data, the reconstructed data provide a means to overcome the limitations posed by short-term observations and are thus of great 500-year timescale. importance for water-resource management over long timescales. Here, we use reconstructed data from the Sanmenxia station to analyze the variation characteristics of the Yellow River at the

\subsubsection{Climate indices}

In addition to analyzing the variation characteristics of the Yellow River streamflow, we also used WTCs to investigate the co-relationships between streamflow and Niño 3.4, the AO, the PDO, and sunspots (Table 1). Niño 3.4 is a representative index for ENSO. An El Niño year occurs when the six-month spatial mean temperature is at least $0.5^{\circ} \mathrm{C}$ higher than average. If the spatial mean temperature is $0.5^{\circ} \mathrm{C}$ lower than average, the year is classed as a La Niña year; otherwise, it is classed as a neutral year (Trenberth, 1997). The Niño 3.4 index is the standardized SST anomaly 
calculated from the HadISST1. It is the area-averaged SST from $5^{\circ} \mathrm{S}-5^{\circ} \mathrm{N}$ and $170 \mathrm{~W}^{\circ}-120^{\circ} \mathrm{W}$ over the Pacific (Trenberth, 1997). The AO refers to an opposing pattern of pressure between the Arctic and the northern middle latitudes (Deser, 2000). The AO index is calculated as the projection of monthly mean $1000 \mathrm{mb}$ height anomalies onto the first empirical orthogonal function (EOF) mode poleward of 20-degrees north using reconstructed data from the 20th Century. The PDO is analyzed from monthly SST anomalies poleward of $20^{\circ} \mathrm{N}$ in the Pacific basin. Sunspots are regions on the solar surface that appear dark because they are cooler than the surrounding photosphere, typically by about $1500 \mathrm{~K}$.

Annual streamflow is closely connected to the climate indices during the rainy season, (July to September), and so averaged Niño 3.4, AO, and PDO indices were used for the analyses in this paper. By comparing results based on annual mean indices, summer mean indices (from July to August), and rainy season mean indices (from July to September), we found that results based on rainy season averaged indices were the most satisfactory. Table 1 summarizes the streamflow series and climate indices discussed in the following sections.

\section{Methods}

The periodicity of streamflow series and the co-varying relationships between streamflow and atmospheric circulation indices / sunspots were analyzed using continuous wavelet transform (CWT) and wavelet transform coherence (WTC).

\subsection{The continuous wavelet transform (CWT)}

For a time series $x_{j}$ of length $N$ with equal sample spacing $\delta t$, the CWT $w_{i}(s)$ at time $t_{i}=i \delta t$ and scale $s$ can be interpreted as an enhanced version of the discrete Fourier transformation $\mathrm{F}(\omega)=\sum_{j} x_{j} \exp \left(i \omega t_{j}\right)$ (Kaiser, 1994). The difference is that the periodic exponential $\exp \left(i \omega t_{j}\right)$ is substituted by a wavelet $\Psi\left(t_{j}-t_{i}, \mathrm{~s}\right)$ (Gedalof et al. 2004), which is a function with zero mean and localized in both time and frequency space (Grinsted et al., 2004). The wavelet function can be stretched or contracted by varying the wavelet scale $s$ as well as translated by changing the localized time index $t_{i}$. The wavelet is analogous to a band-pass filter applied to the time series.

The time series can thus be decomposed dependent on time and scale (Maraun and Kurths, 2004): 
379 where $*$ indicates the complex conjugate and $\mathrm{c}(\mathrm{s})=\sqrt{\frac{\delta t}{s}}$ is the normalization factor that results in $\Psi$ having unit energy. Wavelet power is defined as $\left|W_{i}(s)\right|^{2}$.

Because most practical time series are not cyclical, artifactual edge effects exist. The cone of

382 influence (COI) is the region of the wavelet spectrum in which edge effects cannot be ignored and is defined as the e-folding time for the autocorrelation of wavelet power at each scale (Torrence and Compo, 1998).

The significance level of the wavelet spectrum is analyzed against red noise, which is an appropriate random background spectrum for many geophysical phenomena and which can be modeled as a univariate lag-1 autoregressive (AR-1) process (Torrence and Compo, 1998). We used a significance level of $p<0.05$ to evaluate the statistical significance of our results.

The Morlet wavelet is a non-orthogonal, complex function and is a good choice for achieving a balance between time and frequency. It is defined as

$$
\psi_{0}(\eta)=\pi^{-1 / 4} e^{i \omega_{0} \eta} e^{-\frac{1}{2} \eta^{2}}
$$

where $\omega_{0}=6$ is dimensionless frequency and $\eta$ is dimensionless time (Torrence and Compo, 1998). Additional details about the CWT are given by Grinsted et al. (2004).

\subsection{Wavelet transform coherence (WTC)}

Wavelet transform coherence is a correlation coefficient localized in time and frequency space, which is used to quantify the degree of linear relationship between two non-stationary series in time and frequency domains (Cazelles et al., 2008). Given time series $X$ and $Y$, with wavelet transforms $W_{i}^{x}(s)$ and $W_{i}^{y}(s)$, the wavelet coherence can be defined according to Torrence and Webster (1998) as:

$$
R_{n}^{2}=\frac{\left|S\left(s^{-1} W_{i}^{X Y}(s)\right)\right|^{2}}{S\left(s^{-1}\left|W_{i}^{X}(s)\right|^{2}\right) \cdot S\left(s^{-1}\left|W_{i}^{Y}(s)\right|^{2}\right)}
$$

in which $S$ is a smoothing operator defined by the wavelet type used and

$$
W_{i}^{X Y}(s)=W_{i}^{X}(s) \cdot W_{i}^{Y^{*}}(s)
$$

where $*$ denotes the complex conjugate. $R_{n}^{2}$ takes a value between 0 and 1 , where 0 indicates no correlation between the two time series and 1 indicates that the two time series are perfectly 
correlated with each other. The WTC reveals regions in time-frequency space where the two time series co-vary, but do not necessarily have high power (Keener et al., 2010). In the present work, confidence levels were assessed against red-noise backgrounds. Monte Carlo methods were adopted to estimate the statistical significance of the wavelet coherence; the significance level for each scale was calculated solely from values outside the COI. A detailed description of the calculation of WTCs is provided by Grinsted et al. (2004), who note that that the desirable features of WTCs come at the cost of slightly reduced localization in time-frequency space.

\section{Results and discussion}

\subsection{Continuous wavelet transform (CWT)}

Figure 2 displays the results obtained for the CWT applied to natural streamflow series for the seven hydrological stations of interest along the Yellow River. The thick black contours designate the 5\% significance level against red noise and the pale regions indicate the COI, where edge effects may distort the results. Common features occur in the streamflow wavelet patterns at the 50-year timescale. There are intermittent significant inter-annual oscillations at periods of about 2-6 years from the mid-1950s to the mid-1990s. At the 100-year timescale (streamflow at Longmen and Sanmenxia), both series exhibit high power in the $0-5$-year band from the mid-1950s to the early 1970 s as well as in the $\sim 4$-year band in the 1990s. In general, for streamflow assessed at the 50- and 100-year timescales, interannual oscillations occur intermittently throughout the time series, at increasing periodicities. Figure S1 displays the results obtained for the CWT applied to observed streamflow series at the 50- and 100-year timescales. The results for the observed streamflow series resemble those for the natural streamflow series, overall. Nonetheless, there are some differences. First, certain oscillations in the observed streamflow series persist longer (e.g., the 1-5-year periodicity during the 1970 s -1980 s at Lanzhou, the $\sim 4$-year periodicity in the 1990s at Hekou). Another difference is the emergence of new oscillations in the observed streamflow (e.g., a 2-5-year oscillation in the 1970s at Hekou, a 4-5-year oscillation in the 1990s at Huayuankou) and the disappearance of the $\sim 4$-year periodicities in both series in the 1990s at the 100-year timescale (streamflow at Longmen and Sanmenxia). For streamflow in the middle reaches of the Yellow River at the 500-year timescale (at Sanmenxia), the CWT reveals high power at periodicities of 1-6 years scattered across the 
entire time series, but especially from the early $19^{\text {th }} \mathrm{C}$ onwards. A small-scale decadal oscillation can be seen in the $1750 \mathrm{~s}$, and an intense interdecadal 24-30-year oscillation is apparent from the 1580 s to the 1640 s. Most remarkably, a persistent periodicity of roughly 130 years runs from the 1550 s to the 2010 s, together with a decreasing periodicity from approximately 100 years to about 30 years that emerged in the $19^{\text {th }} \mathrm{C}$. These findings are in agreement with those of Lan et al. (2001) who used power spectrum and variance analysis methods to analyze annual runoff data for the upper Yellow River above Tangnaihai and found similar cycles of $T=2,3,6,13$, and 17 years. The results are also in agreement with Miao and Ni (2009), who used wavelet transforms to analyze streamflow at Sanmenxia since 1470, and found ca 11-, 26-, 67-, and 120-year periods, with the 120-year periodicity being the strongest. The results are also supported by many other studies: Li et al. (2009) analyzed the annual runoff series at Sanmenxia station and reported obvious periodic oscillations of $90-100,50-80,35-50,15-35, \sim 10$, and < 10 years; Liu et al. (2011) applied wavelet analysis to the water discharge at the Lijin station and found three significant periodicities of 2-4, 5-8, and 10-16 years; Yang and Li (2004) applied Morlet wavelets to annual runoff series for the Yellow River Basin and found oscillations with primary periods of $3-4,7-9$, and 11 years.

At the spatial scale, the periodicity is usually continuous, but there are some gradual changes from upstream to downstream. This is because the Yellow River drains a vast basin of great topographical variety. From west to east, the Yellow River runs across four steppes, namely, the Qinghai-Tibetan Plateau, the Inner Mongolia Plateau, the Loess Plateau, and the North China Plain. There are great differences in runoff along the length of the river basin which also contribute to the spatial characteristics.

\section{Figure 2}

When plotted on a temporal scale, the interannual periodicities are discontinuous for all scale series, which may be linked to variations in precipitation and human activities. Runoff is a dynamic response to complex factors, such as precipitation, temperature, ENSO, sunspots, human activity, etc. Of these factors, precipitation and human activity appear to carry the most weight. Annual precipitation decreased at an average rate of $2.96 \mathrm{~mm} / \mathrm{yr}$ in the $1970 \mathrm{~s}$ and $3.82 \mathrm{~mm} / \mathrm{yr}$ in 
the 1990s; the annual mean temperature increased by $0.0256{ }^{\circ} \mathrm{C} / \mathrm{yr}$ between 1951 and 2000 , and pan-evaporation showed great fluctuations, from an increase of $0.7 \mathrm{~mm} / \mathrm{yr}$ during the $1970 \mathrm{~s}$, to a sharp decrease of $13.3 \mathrm{~mm} / \mathrm{yr}$ in the $1980 \mathrm{~s}$, to an increase of $5.2 \mathrm{~mm} / \mathrm{yr}$ in the $1990 \mathrm{~s}$ (Yang et al., 2004). Over the last half century, human activity has greatly influenced streamflow in the Yellow River by water regulation through the construction of dams and reservoirs, the huge consumption of water for irrigation, and water and sediment abstraction. More than a dozen hydropower stations have been built along the main stream of the Yellow river over the last 50 years, and have had a large impact on streamflow (Kong et al., 2016). Moreover, from the 1960s to the 1970s, irrigation water usage increased by $1.05 \mathrm{~mm} / \mathrm{yr}$ (Yang et al., 2004). From the 1970s onwards, water and soil conservation practices have been applied to the Yellow River, with positive effects having since been recorded. The influence of human activity may be seen in the differences in oscillations at Lanzhou, Hekou, and Huayuankou, which are revealed in the CWT results for the natural and observed streamflow series at the 50-year scale. Taking all these factors into consideration, it is no wonder that the interannual periodicity is discontinuous across all the time series. On the contrary, longer-scale periodicity is continuous, as observed in the 500 -year timescale streamflow series.

\subsection{Wavelet transform coherence (WTC)}

Figure 3 shows the WTC results for Niño 3.4 and natural streamflow time series. For streamflow at the 50-year scale, the wavelet coherence with Niño 3.4 highlights mainly interannual covariance, especially over the 5-7 year period and over the $0-2$ year period, with complicated phase differences (confirming the complex relationship between streamflow and Niño 3.4). Both Niño 3.4 and Yellow River streamflow have significant 2-7-year period oscillations in magnitude, confirming the substantial influence of ENSO on streamflow oscillation at this timescale. The present finding of high coherence at the $0-2$, and 5-7-year periods is supported by Labat (2010), who showed that the WTC for Asian freshwater discharge and Niño 3.4 peaked at 2-7-year periodicity. Liu et al. (2011) also found that the associations between water discharge of the Yellow River into the sea and ENSO signal (SST) at 2-8-year timescale were significant. Hao et al. (2008) observed that the precipitation in the middle and lower reaches of the Yellow River had inter-annual oscillations. They also found that the 2-4-year cycle was linked with El Niño 
events, and the precipitation was lower than normal in an El Niño year or the year after. Similar results have also been reported for the Yangtze River: the WTC between ENSO and annual maximum streamflow of Yangtze River indicated that in 1920-1950 high coherence regions occurred with peaks in the 1-8-year band (Zhang et al., 2007). A physical mechanism may be deduced from observations by Wang et al. (2006), who found that global ENSO events directly affect regional precipitation and result in an approximately 51\% decrease in Yellow River water discharge to the sea. This is also supported by Fu et al. (2007), who reported that average annual precipitation was $86.0 \mathrm{~mm}$ higher in La Niña years than in El Niño years, over the long term. Thus, owing to increased precipitation, streamflow in La Niña years was higher than in El Niño years: the difference ranged from $9.2 \%$ at Lanzhou station (upstream) to $22 \%$ at Lijin station (downstream). Fu et al. (2007) also showed that both precipitation and streamflow have temporal and spatial patterns. At the 100-year timescale, streamflow at Longmen and Sanmenxia showed scattered peaks of high interannual coherence with Niño 3.4, especially from the 1940s to the 2000s, with complicated patterns of phase difference. In addition, around 1940, there is a significant periodicity of roughly $8-10$ years that has an approximately anti-phase relationship (a lag of 4-5 years) in the middle Yellow River. Figure S2 shows the WTC results for Niño 3.4 and the observed streamflow time series, which are similar on the whole to the results for Niño 3.4 and the natural streamflow time series. Nevertheless, some differences are apparent. Significant periodicities of 2-4 years in the 1980s and 6-years in the 1990s at Lanzhou and Hekou, and 3-6 years in the 1980s at Huayuankou, are revealed in the WTC results for Niño 3.4 and the observed streamflow time series. However, the annual oscillations in the 1970s and 1990s at Huayuankou and Lijin are more evident in the WTC results for Niño 3.4 and the natural streamflow time series. The differences mostly occur in the past 50 years, so may arise from anthropogenic influences.

The WTCs between the AO and natural streamflow over different timescales are depicted in figure 4. For streamflow measured over the 50-year timescale, there is a 4-6-year band of high covariance around the 1970s and the 1990s, and the in-phase relationship indicates a positive correlation. The most prominent power occurs in the 8-12-year oscillation band that stretches from the 1970 s to the 1990 s, with the AO leading streamflow by approximately $45^{\circ}$ (1-1.5 years). 
For streamflow over the 100 -year timescale, interannual oscillations with an approximately 5-6-year periodicity in the 1940s and a 2-6-year periodicity in the 1970s and 1990s all have an 530 approximately in-phase relationship, which means the AO and natural streamflow are positively correlated during these periods. There is also a prominent decadal oscillation from the 1960s to the 1980s with the AO leading streamflow by approximately $45^{\circ}$ to $90^{\circ}$, which means that streamflow lags behind AO by around $1-1.5$ years to $2-3$ years during this period. The WTCs between the AO and observed streamflow over different timescales are depicted in figure S3. The duration of decadal periodicities is relatively longer in the results for observed streamflow at Lanzhou, Hekou, Huayuankou, Lijin, Longmen, and Sanmenxia.

In the middle Yellow River, scattered periodicities ranging from 1 to 10 years with complicated phase-difference patterns are observed intermittently from the 1870 s to the 1970 s, with a trend toward increasing periodicity over that time. The most prominent covariance between the AO and streamflow in the middle Yellow River is an approximately 32-year band from the 1880 s to the 2000 s, with AO leading streamflow by $270^{\circ}$ (about 24 years); however, half of the region lies in the COI. The results agree with Labat (2010) who found that the decadal and multidecadal variability of Asian freshwater discharge appeared to be driven by the AO. In addition, Gong and Wang (2003) studied winter climate and AO from 1899 to 1994 and found that the AO had a significant influence on both temperature and precipitation at the interdecadal timescale (10-40 years). The physical mechanism behind these results may be linked to the two AO phases: a "positive phase" with relatively low pressure over the polar region and high pressure at mid-latitudes, and a "negative phase", which shows the opposite pressure pattern. In the positive phase, high pressure at mid-latitudes drives ocean storms farther north (Labat, 2010), producing increases in winter temperatures and precipitation over much of China (Gong and Wang, 2003). Jevrejeva and Moore (2001) showed that the AO exhibits power at periods of 2.3, 7.8, and 13.9 years, so it is perhaps not surprising that the WTC for streamflow and AO displays interannual and decadal periodicities.

The WTCs between the PDO and natural streamflow over different timescales are depicted in

555 figure 5. For natural streamflow at the 50-year timescale, there are intermittent significant 
oscillations, with periodicities increasing from 1 year in the 1960 s, to $2-5$ years in the 1970 s, to $5-$ 6 years in the 1980s to 1990 s, with gradually varying phase differences. Within the COI zone, decadal oscillations appear in the 1950s at upstream stations and in the 1950s to 1970 s at downstream stations. For the century-scale time series, scattered interannual periodicities occur across the whole period, with complicated phase-difference patterns. Decadecal periodicities occur in the middle stream during the 1920 s to 1930 s. Bidecadal oscillations may be discerned in the middle stream during the 1980 s to 2000 s, but fall within the COI zone. The WTCs between the PDO and observed streamflow over different timescales are depicted in Figure S4, and have almost identical characteristics. According to Mantua and Hare (2002), 20 ${ }^{\text {th }}$ century PDO fluctuations were most energetic at two dominant periodicities: 15-25 years and 50-75 years, when the warm phase and the cold phase were almost equally split. During the cool phase of the PDO, there are typically cooler-than-average temperatures and above-average rainfall (Labat, 2010). The decadal and bidecadal oscillations may be explained by the PDO fluctuations. The significant interannual periodicity observed in the WTC for streamflow and the PDO may arise from the fact that runoff is a dynamic combination of complex factors.

\section{Figure 5}

Figure 6 depicts the WTCs for sunspot number and natural streamflow over different timescales. For streamflow at the 50- and 100-year timescales, regions of high covariance are mainly concentrated in scattered interannual bands with periodicity varying from 1 year to 6 years. Phase differences vary according to the different periods. The scattered interannual periodicities may be explained by data from Krivova and Solanki (2002), who showed that sunspot number has had a 1.3-year periodicity since 1749; the interannual periodicities can be regarded as multiples of this 1.3 -year period. For streamflow at the 500-year scale, scattered periodicities of about $8-14$ years occur intermittently during the $1730 \mathrm{~s}-1760 \mathrm{~s}$, the $1830 \mathrm{~s}-1900 \mathrm{~s}$, and the $1940 \mathrm{~s}-1950 \mathrm{~s}$, all with complicated phase differences. In addition, there is prominent covariance with a periodicity of roughly 80 years that runs from the 1760 s to the 2000 s, with streamflow leading sunspot number by approximately $45^{\circ}$; however, much of this region falls within the COI. The presence of decadal and multidecadal oscillations is supported by Li et al. (2009), who showed that runoff in 
the Yellow River was correlated with sunspot number during the period from 1700 to 2003 at 11-year and 60-year timescales. These correlations are reasonable because the numbers of sunspots predominate at 11-year and 60-year periodicities (Li et al., 2009). Figure S5 depicts the WTCs for sunspot number and observed streamflow over different timescales. Figure S5 shows that decadal periodicity of roughly $10-14$ years is present in observed streamflow in the lower Yellow River from the 1990s to 2010s, though it should be noted that roughly half these results lie in the COI zone. For observed streamflow at the 100-year timescale, there is high covariance in a 1-3-year band from the late 2000 s to the early 2010 s that has an anti-phase phase difference (i.e. a lag of 0.5 to 1.5 years), but a large portion of these results also lies within the COI zone. A 912-year band from the 2000s to the early 2010s also lies inside the COI zone, with sunspot number leading streamflow by $90^{\circ}$ (2.25-3 years). Notably, a band with 8-10-year periodicity occurs in the middle Yellow River from the late 1930s to the mid-1950s, with sunspot number leading streamflow by $90^{\circ}$ ( $2-2.5$ years). Such oscillations are apparently stronger in the observed streamflow than in the natural streamflow, and may be attributed to the effect of human activities.

\section{Figure 6}

The results demonstrate that solar activities have complicated effects on runoff in the Yellow River. The sun provides $99.97 \%$ of the earth's energy budget (Nurtaev, 2016). Increases in the number of sunspots represent a strengthening of solar activity because sunspots are the source of solar flares. When solar activity intensifies, the increasing number of sunspots radiates more energy to the atmosphere, heating the earth on average the most near the equator and least at the poles (Nurtaev, 2016). This energy evaporates water, causes atmospheric convection, and is transported polewards by winds, thus reducing the equator-to-pole temperature gradient. Therefore, the number of sunspots can be taken as an indicator of climate trends. Increasing numbers of sunspots generally lead to strengthening of longitudinal circulations and weakening of latitudinal circulations. The former is conducive to latitudinal air mass movements and formation of precipitation. The latter generally favors hot lows over the Qinghai-Tibet Plateau and accounts for the increase in precipitation and runoff in the upper Yellow River. Conversely, runoff in the headwaters of the Yellow River will decrease when radial winds weaken and zonal winds intensify (Lan et al., 2001). 
Furthermore, when abnormal solar activity increases, the area covered by Antarctic ice is reduced at least until the following year (Wang et al., 1997). Atmospheric circulation is therefore also affected during the following year, resulting in abundant precipitation. The combined effect will be excess runoff in the Yellow River basin.

\section{Conclusions}

The Yellow River has been suffering from severe water scarcity over the past half century. In this paper, we used CWTs to investigate the periodicity of natural, observed, and reconstructed streamflow in the Yellow River at 500-, 100-, and 50-year timescales. We also used WTCs to assess the covariance of streamflow series with several atmospheric circulation indices and with sunspot number. Our findings are summarized below.

At the temporal scale, the CWT results show intermittent oscillations at increasing periodicities from 1 to 6 years in all streamflow series (500-, 100-, and 50-year timescales). Interannual periodicities were discontinuous for all the series; this may be linked to varied precipitation and human activities. Conversely, we observed continuous, longer-scale periodicity at the 500-year timescale. In addition, a significant periodicity of about $24-30$ years was also identified at the 500-year timescale. The most remarkable feature of streamflow at the 500-year timescale was a persistent periodicity of roughly 130 years and later oscillations that decreased in periodicity from approximately 100 years to about 30 years.

The periodicities in the CWT results were generally spatially continuous. There were some gradual changes from upstream to downstream reaches in the Yellow River as a result of changing topography and varying discharge along the stream.

According to the WTC results, streamflow at the 50-year timescale was significantly correlated with atmospheric circulation indices and sunspot number for intermittent interannual periodicities, namely, 0-2 and 5-7 years for Niño 3.4, 4-6 years for the AO, and 1-6 years for the PDO and sunspots. Moreover, streamflow at the 50-year timescale was correlated with the AO (812-year periodicity) and with the PDO (brief decadal or bidecadal periodicities). For streamflow at the 100-year timescale, apart from scattered interannual periodicities, there were significant decadal oscillations, with streamflow in the middle Yellow River correlated with Niño 3.4 at periodicity of $8-10$ years, and with the $\mathrm{AO}$ and sunspots at decadal periodicity. Notably, 
streamflow at the 500-year timescale was significantly correlated with the $\mathrm{AO}$ at a periodicity of approximately 32 years and with sunspots at a periodicity of approximately 80 years.

The WTC results indicate that atmospheric circulation indices and sunspots have had substantial impacts on variations in observed, natural, and reconstructed streamflow in the Yellow River over 500-, 100-, and 50-year timescales. Global ENSO events directly affected regional precipitation and resulted in variations in the Yellow River streamflow, with 0-2 and 5-7-year periodicities. Positive AO increased the temperature and precipitation over most of China during the winter; Yellow River streamflow correlated with AO over 4-6-year and 32-year periodicities. During the cool phase of the PDO, there were typically cooler-than-average temperatures and above-average rainfall, resulting in interannual, decadal, and bidecadal fluctuations in streamflow in the Yellow River. Abnormal sunspot activity affected streamflow by influencing both latitudinal and longitudinal atmospheric circulations and by altering the amount of Antarctic ice, which eventually led to abundant precipitation and excess runoff in the Yellow River basin. In this way, sunspot activity affected variation in the Yellow River streamflow over interannual, decadal, and 80-year periodicities. In summary, we deduce that atmospheric circulation indices modulate streamflow by affecting temperature and precipitation. Sunspots impact streamflow variability through their effects on atmospheric circulation and resulting abundant precipitation. The CWT and WTC oscillations for observed streamflow were sustained over longer periods, for the most part, than those for natural streamflow, which may be attributed to anthropogenic influences.

The WTC periodicities were generally continuous at the spatial scale, with gradual changes evident from upstream to downstream; this is to be expected given that the topography and runoff vary greatly along the stream of the Yellow River. At the temporal scale, periodicities were generally continuous over short timescales but discontinuous over longer timescales.

\section{Acknowledgments}

Funding for this research was provided by the National Natural Science Foundation of China (no. 41001153), Beijing Higher Education Young Elite Teacher Project and State Key Laboratory of Earth Surface Processes and Resource Ecology.

\section{References}


Arnell, N.W., 1999. Climate change and global water resources. Glob. Environ. Change 9, S31-S49.

Briciu, A.E., Mihăilă, D., 2014. Wavelet analysis of some rivers in SE Europe and selected climate indices. Environ. Monit. Assess. 186(10), 6263-6286.

Brito-Castillo, L., Díaz-Castro, S., Salinas-Zavala, C.A., Douglas, A.V., 2003. Reconstruction of long-term winter streamflow in the Gulf of California continental watershed. J. Hydrol. 278(1): 39-50.

Cazelles, B., Chavez, M., Berteaux, D., Ménard, F., Vik, J.O., Jenouvrier, S., Stenseth, N.C., 2008. Wavelet analysis of ecological time series. Oecologia 156(2), 287-304.

China Meteorological Administration (CMA), 1981. Yearly Charts of Dryness/wetness in China for the Last 500-year Period. SinoMaps Press, Beijing (in Chinese).

Coulibaly, P., Burn, D.H., 2005. Spatial and temporal variability of Canadian seasonal streamflows. J. Clim. 18(1), 191-210.

Deser, C., 2000. On the teleconnectivity of the "Arctic Oscillation”. Geophys. Res. Lett. 27(6), $779-782$.

Fang, X., Xiao, L., Wei, Z., 2012. Social impacts of the climatic shift around the turn of the 19th century on the North China Plain. Sci. China Earth Sci. 56(6), 1044-1058.

Fu, G.B., Charles, S.P., Viney, N.R., Chen, S.L., Wu, J.Q., 2007. Impacts of climate variability on stream-flow in the Yellow River. Hydrol. Process. 21(25), 3431-3439.

Gaucherel, C., 2002. Use of wavelet transform for temporal characterisationof remote watersheds. J. Hydrol. 269(3), 101-121.

Gedalof, Z., Peterson, D.L., Mantua,N.J., 2004. Columbia River flow and drought since 1750. J. Am. Water Resour. Assoc.40(6), 1579-1592.

González-Lemos, S., Müller, W., Pisonero, J., Cheng, H., et al., 2015. Holocene flood frequency reconstruction from speleothems in northern Spain,. Quatern. Sci. Rev., 127, 129-140.

Gobena, A.K., Gan, T.Y., 2009. The role of Pacific climate on low-frequency hydroclimatic variability and predictability in Southern Alberta, Canada. J. Hydrometeor.10(6), $1465-1478$.

Gong, D.Y., Wang, S.W., 2003. Influence of Arctic Oscillation on winter climate over China. J. Geogr. Sci. 13(2), 208-216. 
Gou, X.H., Deng, Y., Chen, F.H., Yang, M.X., Fang, K.Y., Gao, L.L., Yang, T., Zhang, F., 2010. Tree ring based streamflow reconstruction for the Upper Yellow River over the past 1234 years. Chin. Sci. Bull. 55(36), 4179-4186.

Grinsted, A., Moore, J.C., Jevrejeva, S., 2004. Application of the cross wavelet transform and wavelet coherence to geophysical time series. Nonlinear Process. Geophys. 2004, 11 (5/6), 561-566.

Grove, C. A., Zinke, J., Peeters, F., Park, W. ,et.al., 2013. Madagascar corals reveal a multidecadal signature of rainfall and river runoff since 1708, Clim. Past., 9(2), 641-656.

Hao, Z., Zheng, J., Ge, Q., 2008. Precipitation cycles in the middle and lower reaches of the Yellow River (1736-2000). J. Geogr. Sci. 18(1), 17-25.

He, B., Miao, C., Shi, W., 2013. Trend, abrupt change, and periodicity of streamflow in the mainstream of Yellow River, Environ. Monit. Assess., 185(7), 6187-6199.

Hidalgo, H.G., Piechota, T.C., Dracup, J.A., 2000. Alternative principal components regression procedures for dendrohydrologic reconstructions. Water Resour. Res. 36(11), 3241-3249.

Huang, S., Huang, Q., Chang, J., Zhu, Y., Leng, G., Xing L., 2015. Drought structure based on a nonparametric multivariate standardized drought index across the Yellow River basin, China, J. Hydrol., 530, 127-136.

Isdale, P.J., 1984, Fluorescent bands in massive corals record centuries of coastal rainfall, Nature, 310(5978), 578-579.

Isdale, P. J., Stewart, B. J., Tickle, K. S. , Lough, J. M., 1998. Palaeohydrological variation in a tropical river catchment: a reconstruction using fluorescent bands in corals of the Great Barrier Reef, Australia, The Holocene, 8(1), 1-8.

Jevrejeva, S., Moore, J.C., 2001. Singular spectrum analysis of Baltic Sea ice conditions and large-scale atmospheric patterns since 1708. Geophys. Res. Lett. 28(23), 4503-4506.

Kaiser, G., 1994. A Friendly Guide to Wavelets. Birkhäuser, Boston, 1994.

Keener, V.W., Feyereisen, G.W., Lall, U., Jones, J.W., Bosch, D.D., Lowrance, R., 2010. El-Niño/Southern Oscillation (ENSO) influences on monthly $\mathrm{NO}_{3}$ load and concentration, stream flow and precipitation in the Little River Watershed, Tifton, Georgia (GA). J. Hydrol. 381(3), 352-363.

Kong, D.X., Miao, C.Y., Wu, J.W., Borthwick, A.G.L., Duan, Q.Y., 2017. Environmental impact 
assessments of the Xiaolangdi Reservoir on the most hyper-concentrated laden river, Yellow River, China. Environ. Sci. Pollut. Res. 24, 4337-4351.

Krivova, N.A., Solanki, S.K., 2002. The 1.3-year and 156-day periodicities in sunspot data: Wavelet analysis suggests a common origin. Astron. Astrophys. 394(2), 701-706.

Kumar, P., Foufoula-Georgiou, E., 1997. Wavelet analysis for geophysical applications. Rev. Geophys. 35(4), 385-412.

Labat, D., 2010. Cross wavelet analyses of annual continental freshwater discharge and selected climate indices. J. Hydrol. 385(1), 269-278.

Labat, D., Ababou, R., Mangin, A., 2000. Rainfall-runoff relations for karstic springs. Part II: continuous wavelet and discrete orthogonal multiresolution analyses. J. Hydrol. 238(3), $149-178$.

Labat, D., Goddéris, Y., Probst, J.L., Guyot, J.L., 2004. Evidence for global runoff increase related to climate warming. Adv. Water Resour. 27(6), 631-642.

Labat, D., 2008. Wavelet analysis of the annual discharge records of the world's largest rivers. Adv. Water Resour. 31(1), 109-117.

Lan, Y.C. , Kang, E.S., Ma, Q.J., Zhang, J.S., Chen, R.S., 2001. Runoff of the upper Yellow River above Tangnag: characteristics, evolution and changing trends. J. Geogr. Sci. 11(3), 297-304.

Li, C.H., Yang, Z.F., Huang, G.H., Li, Y.P., 2009. Identification of relationship between sunspots and natural runoff in the Yellow River based on discrete wavelet analysis. Expert Syst. Appl. $36(2), 3309-3318$.

Li, D., Jiang, X.H.,Wang, Y.M., Li, H.L., 2001. Analysis of calculation of natural runoff in the Yellow River Basin. People's Yellow River. 23(2), 35-37 (in Chinese with English abstract).

Li, J.F., Yuan, Y.J., 1997. 360 years' runoff reconstruction in the Urumqi River basin using tree rings. Quatern. Sci. 2,131-137 (in Chinese with English abstract).

Littell, J.S., Pederson, G.T., Gray,S.T., et al., 2016. Reconstructions of Columbia River Streamflow from Tree-Ring Chronologies in the Pacific Northwest, USA. J .Am. Water Resour. Assoc. 52(5):1121-1141.

Liu, F., Chen, S., Peng, J., Chen, G., 2011. Temporal variability of water discharge and sediment load of the Yellow River into the sea during 1950-2008. J. Geogr. Sci. 21(6), 1047-1061. 
Liu, Y., Sun, J., Song, H., Cai, Q., Bao, G., Li, X., 2010. Tree-ring hydrologic reconstructions for the Heihe River watershed, western China since AD 1430. Water Res. 44(9), 2781-2792.

Lough, J. M., Lewis, S. E. , Cantin, N. E., 2015. Freshwater impacts in the central Great Barrier Reef: 1648-2011, Coral Reefs, 34(3), 739-751.

Mantua, N.J., Hare, S.R., 2002. The Pacific Decadal Oscillation. J. Oceanogr. 58(1), 35-44.

Maraun, D., Kurths, J., 2004. Cross wavelet analysis: significance testing and pitfalls. Nonlinear Process. Geophys. 11(4), 505-514.

Miao C.Y., Kong D.X., Wu J.W., Duan Q.Y., 2016. Functional degradation of the water-sediment regulation scheme in the lower Yellow River: Spatial and temporal analyses. Sci. Total Environ. 551-552, 16-22.

Miao, C.Y., Ni, J.R., 2009. Variation of natural streamflow since 1470 in the middle Yellow River, China. Int. J. Environ Res. Public Health 6(11), 2849-2864.

Miao, C.Y., Ni, J.R. Borthwick, A.G.L., Yang, L., 2011. A preliminary estimate of human and natural contributions to the changes in water discharge and sediment load in the Yellow River. Glob. Planet. Change, 76(3-4): 196-205.

Miao, C., Ni, J., Borthwick, A.G.L., 2010. Recent changes of water discharge and sediment load in the Yellow River basin, China. Prog. Phys. Geogr. 34(4), 541-561.

Milly, P.C.D., Dunne, K.A., Vecchia, A.V., 2005. Global pattern of trends in streamflow and water availability in a changing climate. Nature 438(7066), 347-350.

Milliman, J.D., Farnsworth, K.L., Jones, P.D., Xu, K.H., Smith, L.C., 2008. Climatic and anthropogenic factors affecting river discharge to the global ocean, 1951-2000. Glob. Planet. Change 62(3), 187-194.

Nalley, D., Adamowski, J., Khalil, B., Ozga-Zielinski, B., 2013. Trend detection in surface air temperature in Ontario and Quebec, Canada during 1967-2006 using the discrete wavelet transform, Atmos. Res. 132-133, 375-398.

Nalley, D., Adamowski, J., Khalil, B., Biswas ,A., 2016. Inter-annual to inter-decadal streamflow variability in Quebec and Ontario in relation to dominant large-scale climate indices, J. Hydrol., 536, 426-446.

Niu, J., and Chen, J., 2016. A wavelet perspective on variabilities of hydrological processes in conjunction with geomorphic analysis over the Pearl River basin in South China, J. Hydrol. 
542, 392-409.

797

Nourani, V., Baghanam, A. H., Adamowski, J., Gebremichael, M., 2013. Using self-organizing maps and wavelet transforms for space-time pre-processing of satellite precipitation and runoff data in neural network based rainfall-runoff modeling, J. Hydrol. 476, 228-243.

Nurtaev, B., 2016. Helioclimatology of the Alps and the Tibetan Plateau, Earth Sci., 5(2), 19-25.

Peng Z, He X, Zhang Z, et al., 2002. Correlation of coral fluorescence with nearshore rainfall and runoff in Hainan Island, South China Sea. Prog. Nat. Sci., 12(1): 41-44 (in Chinese with English abstract).

Qin, N., Jin, L., Shi, X., et al., 2004. A 518-year runoff reconstruction of Tongtian river basin using tree-ring width chronologies. Acta Geogr. Sin., 59(4): 550-556 (in Chinese with English abstract).

Shiau, J.T., Feng, S., Nadarajah, S., 2007. Assessment of hydrological droughts for the Yellow River, China, using copulas. Hydrol. Process. 21(16), 2157-2163.

Smith, L.C., Turcotte, D.L., Isacks, B.L., 1998. Stream flow characterization and feature detection using a discrete wavelet transform. Hydrol. Process. 12(2), 233-249.

Sun, W.G., Cheng, B.Y., Li, R., 2010. Seasonal variations of runoff and its wavelet correlations with regional climate in source region of the Yellow River. J. Desert Res. 30(3), 712-721(in Chinese with English abstract)..

Sun, J., Liu,Y., Wang,Y., Bao,G., Sun, B., 2013. Tree-ring based runoff reconstruction of the upper Fenhe River basin, North China, since 1799 AD, Quatern. Int., 283, 117-124,

Oki T., Kanae S., 2006. Global hydrological cycles and world water resources. Science 313(5790), 1068-1072.

Pathak, P., Kalra, A., Ahmad, S., Bernardez, M., 2016. Wavelet-Aided Analysis to Estimate Seasonal Variability and Dominant Periodicities in Temperature, Precipitation, and Streamflow in the Midwestern United States, Water Resour. Manag. 30(13), 4649-4665.

Tamaddun, K. A., Kalra, A., Ahmad, S., 2016, Wavelet analysis of western U.S. streamflow with ENSO and PDO, J. Water Clim. Change 8(1), 26-39.

Tan, L., An, Z., Huh, C. A., Cai, Y., et al., 2014. Cyclic precipitation variation on the western Loess Plateau of China during the past four centuries, Sci. Rep. 4, 6381,

Torrence, C., Compo, G.P., 1998. A practical guide to wavelet analysis. Bull. Am. Meteorol. Soc. 
Torrence, C., Webster, P.J., 1998. Interdecadal changes in the ENSO-monsoon system. J. Climate 12(8), 2679-2690.

829

Trenberth, K.E., 1997. The definition of El Niño. Bull. Am. Meteorol. Soc. 78(12), 2771-2777.

Wang G.A., Shi, F.C., Zheng, X.Y., Gao, Z.D., Yi, Y.J., Ma, G.A., Mu, P., 1999. Natural annual runoff estimation from 1470 to 1918 for Sanmenxia Gauge Station of Yellow River. Adv. Water Sci. 10(2), 170-176 (in Chinese with English abstract).

Wang, H.J., Yang, Z.S., Saito, Y., Liu, J. P., Sun, X.X., 2006. Interannual and seasonal variation of the Huanghe (Yellow River) water discharge over the past 50 years: Connections to impacts from ENSO events and dams. Glob. Planet. Change. 50(3), 212-225.

Wang, H., Chen, Y., Li, W., 2013. Hydrological extreme variability in the headwater of Tarim River: links with atmospheric teleconnection and regional climate, Stoch. Environ. Res. Risk Assess. 28(2), 443-453.

Wang, L., Sun, X., 2016. Multi-timescale characteristics of runoff and sediment discharge along Lower Yellow River and their coupling analysis. Water Resour. \& Water Eng. 47(2), 58-62. (in Chinese with English abstract).

Wang, Y.Z., Yue, Y.J., Peng, Z.F., Wang, G.Q., 1997. The relationship between sunspot activity and the runoff and flood in Yellow River. Water Resour. \& Water Eng. 8(3), 30-38 (in Chinese with English abstract).

Wei, Y., Jiao, J., Zhao, G., Zhao, H., He, Z., Mu, X. 2016. Spatial-temporal variation and periodic change in streamflow and suspended sediment discharge along the mainstream of the Yellow River during 1950 - 2013. Catena 140, 105-115.

Woodhouse, C.A., 2001. A tree-ring reconstruction of streamflow for the Colorado Front Range. J .Am. Water Resour. Assoc. 37(3), 561-569.

Wu, J.W., Miao, C.Y., Wang, Y.M., Duan, Q.Y., Zhang, X.M., 2017. Contribution analysis of the long-term changes in seasonal runoff on the Loess Plateau, China, using eight Budyko-based methods. J. Hydrol. 545: 263-275

Xiao, L., Fang, X., Zheng, J., Zhao ,W. , 2015. Famine, migration and war: Comparison of climate change impacts and social responses in North China between the late Ming and late Qing dynasties. The Holocene, 25(6), 900-910. 
$\mathrm{Xu}, \mathrm{J} ., 2004$. A study of anthropogenic seasonal rivers in China. Catena 55(1), 17-32.

$\mathrm{Xu}, \mathrm{J} ., 2015 \mathrm{a}$, Paleo-hydrologic reconstruction based on stalagmite $\delta 18 \mathrm{O}$ and re-assessment of river flow above the Danjiangkou Dam, China. Climatic Change, 130(4), 619-634.

$\mathrm{Xu}, \mathrm{J} ., 2015 \mathrm{~b}$, River flow reconstruction using stalagmite oxygen isotope $\delta 180$ : An example of the Jialingjiang River, China, J. Hydrol, 529, 559-569.

Xu, K., Milliman, J.D., Xu, H., 2010. Temporal trend of precipitation and runoff in major Chinese Rivers since 1951. Glob. Planet. Change 73(3), 219-232.

Yadava, M. G., Ramesh, R., 2005. Monsoon reconstruction from radiocarbon dated tropical Indian speleothems. The Holocene, 15(1), 48-59.

Yang, D., Li, C., Hu, H., Lei, Z., Yang, S., Kusuda, T., Koike, T., Musiake, K., 2004. Analysis of water resources variability in the Yellow River of China during the last half century using historical data. Water Resour Res. 40(6), 1-12.

Yang, Z.F, Li, C.H., 2004. Abrupt and periodic change of the annual natural runoff in the subregions of the Yellow River. J. Mount. Res. 22(2), 140-146 (in Chinese with English abstract).

Yang, Z.S., Milliman, J.D., Galler, J., Liu, J.P., Sun, X.G, 1998. Yellow River's water and sediment discharge decreasing steadily. EOS Trans AGU, 79(48), 589-592.

Yarleque, C., Vuille, M., Hardy, D. R., Posadas, A., Quiroz, R., 2016, Multiscale assessment of spatial precipitation variability over complex mountain terrain using a high-resolution spatiotemporal wavelet reconstruction method, J. Geophys. Res. Atmos., 121(20), $12,198-112,216$.

Yellow River Conservancy Commission (YRCC), 2012. Yellow River Water Resources Bulletin (in Chinese).

Ye, Y. and Fang, X., 2015. Land reclamation in the farming-grazing transitional zone of northeast China: 1644-1930, Prof. Geogr. 67:1, 8-16.

Yu, S., Yang, J., Liu, G., Yao, R., Wang, X., 2015. Improvement for the multi-scale periodic characteristics revealing of precipitation signals and its impact assessment on soil hydrological process by combining HHT and CWT approaches. Nat.Hazards Earth Syst. Sci. 15(3), 393-407.

Zhang, J.F., Li, G.M., Liang, S., 2012. The response of river discharge to climate fluctuations in 
887 Zhang, J., Man, Z., Song, J., Li, T., 2015. Sequence reconstruction and characteristics diagnosis of areal precipitation in the middle Yellow River from May to October during 1765-2010. Acta Geogr. Sin., 70(7), 1101-1103 (in Chinese with English abstract).

890

Zhang, Q, Xu, C.Y., Jiang, T., Wu, Y.J., 2007. Possible influence of ENSO on annual maximum streamflow of Yangtze River, China. J. Hydrol. 333, 265-274.

892 
Table 1 Streamflow series and climate indices used in the paper

\begin{tabular}{l|l|l|l}
\hline Index & & Period & Source \\
\hline Natural streamflow & Tangnaihai & $1956-2015$ & YRCC \\
Observed streamflow & Lanzhou & $1956-2015$ & \\
& Hekou & $1956-2015$ & \\
\hline Reconstructed streamflow & Sanmenxia & $1956-2015$ & \\
\hline Niño 3.4 & Longmen & $1956-2015$ & \\
PDO & Sanmenxia & $1919-2015$ & \\
\hline AO & & $1870-2015$ & YRCC, Wang et al. (1999) \\
\hline
\end{tabular}


897 Figure 1. The Yellow River basin: location of hydrological stations

898 Figure 2. Continuous wavelet transform for the 1956 - 2015 time series (natural streamflow at 899 Tangnaihai, Lanzhou, Hekou, Huayuankou, Lijin), the 1919 - 2015 time series (natural 900 streamflow at Longmen, Sanmenxia), and the 1470 - 2015 time series (reconstructed streamflow 901 at Sanmenxia). Thick contours denote 5\% significance levels against red noise. Pale regions 902 denote the cone of influence (COI) where edge effects might distort the results.

903 Figure 2. Wavelet transform coherence for Niño 3.4 and natural and reconstructed streamflow. 904 Thick contours denote 5\% significance levels against red noise. Pale regions denote the cone of 905 influence (COI) where edge effects might distort the results. Small arrows denote the relative 906 phase relationship (in-phase, arrows point right; anti-phase, arrows point left).

907 Figure 4. Wavelet transform coherence for the AO and natural and reconstructed streamflow.

908 Thick contours denote $5 \%$ significance levels against red noise. Pale regions denote the cone of influence (COI) where edge effects might distort the results. Small arrows denote the relative phase relationship (in-phase, arrows point right; anti-phase, arrows point left).

Figure 3. Wavelet transform coherence for the PDO and natural and reconstructed streamflow. Thick contours denote $5 \%$ significance levels against red noise. Pale regions denote the cone of influence (COI) where edge effects might distort the results. Small arrows denote the relative phase relationship (in-phase, arrows point right; anti-phase, arrows point left).

Figure 4. Wavelet transform coherence for sunspot number and natural and reconstructed streamflow. Thick contours denote $5 \%$ significance levels against red noise. Pale regions denote the cone of influence (COI) where edge effects might distort the results. Small arrows denote the relative phase relationship (in-phase, arrows point right; anti-phase, arrows point left). 


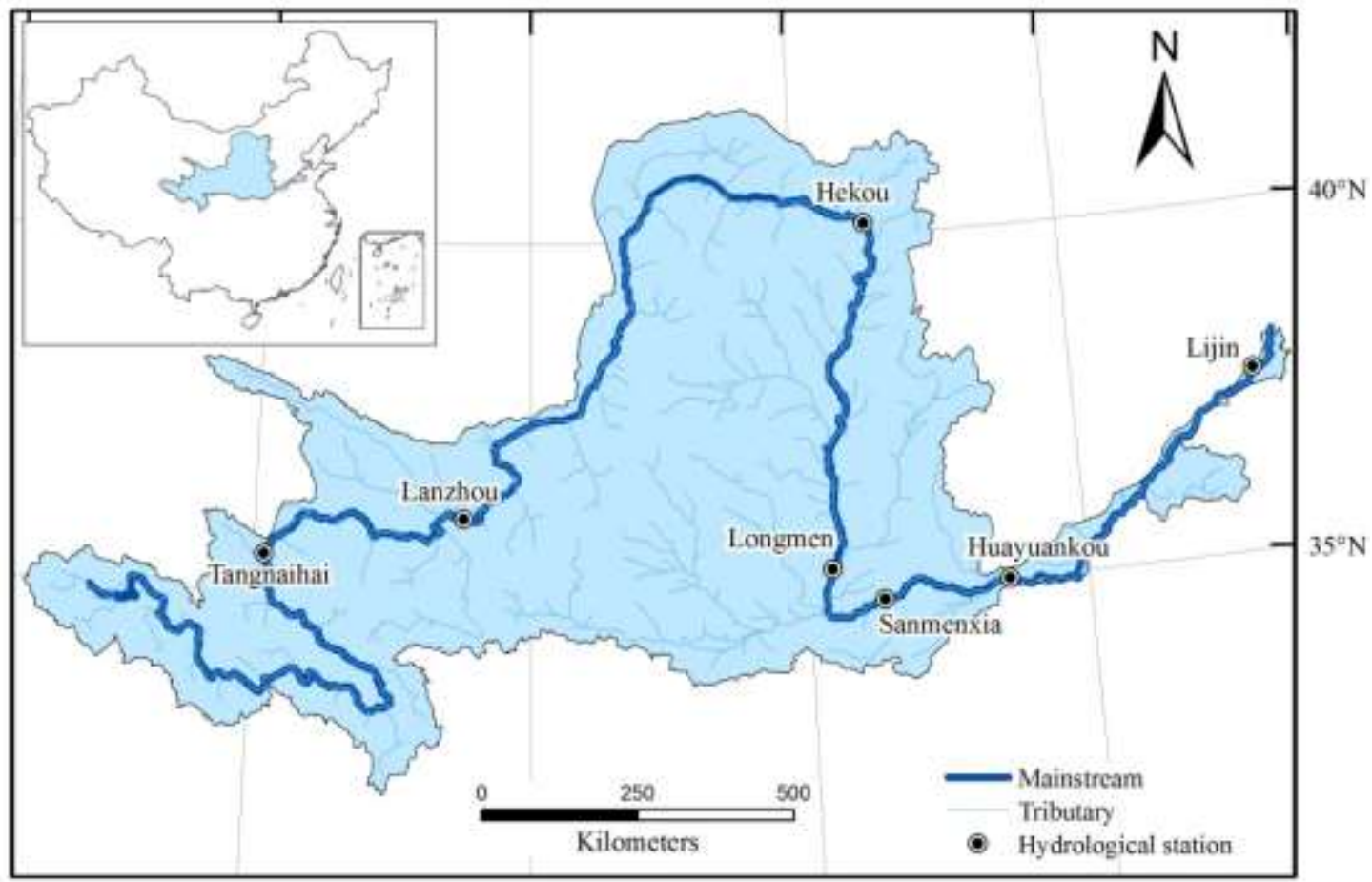

922

Figure 5. The Yellow River basin: location of hydrological stations 

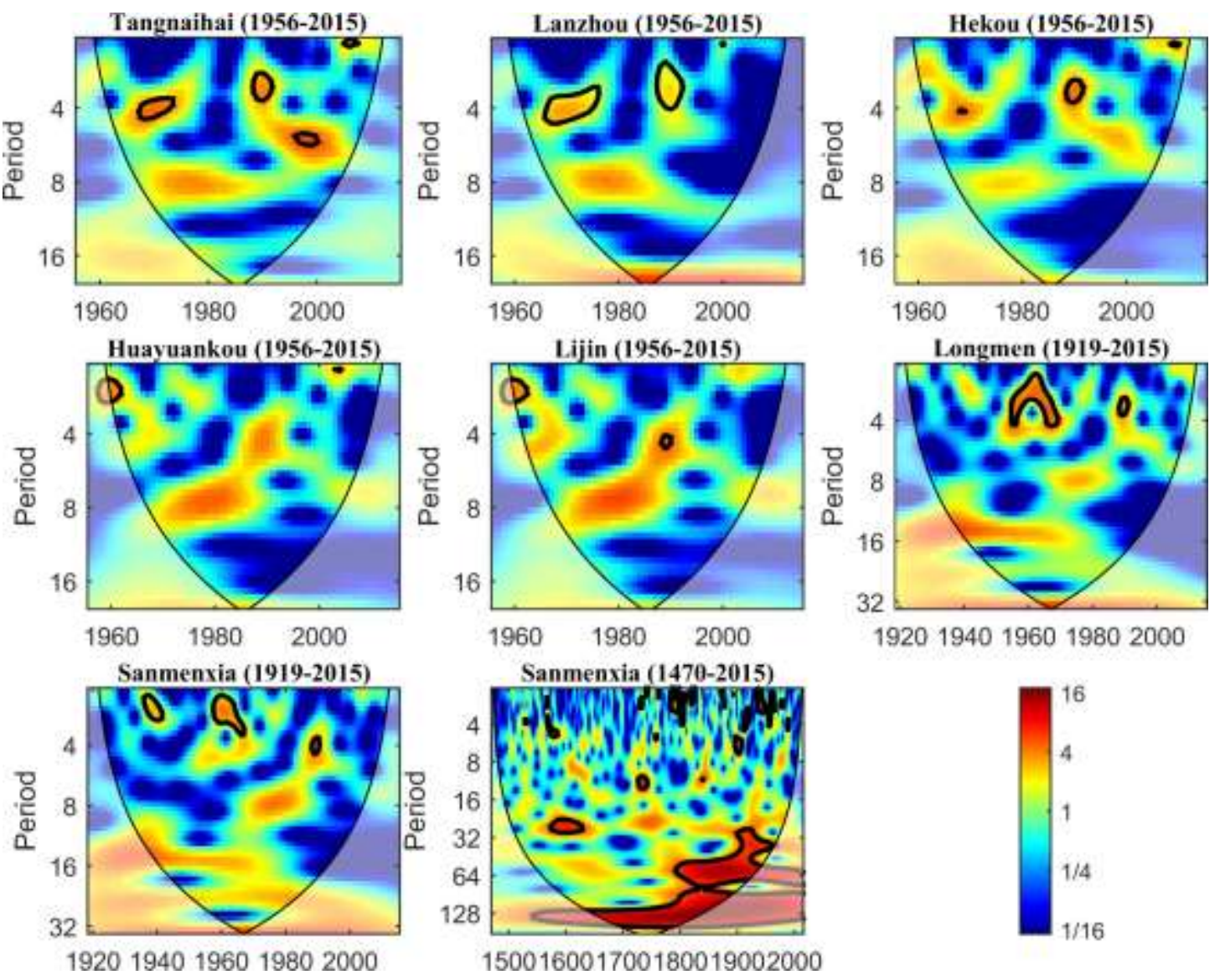

927 Figure 2. Continuous wavelet transform for the 1956 - 2015 natural time series (Tangnaihai,

928 Lanzhou, Hekou, Huayuankou, Lijin), the 1919 - 2015 time series (Longmen, Sanmenxia), and 929 the 1470 - 2015 natural time series (Sanmenxia). Thick contours denote 5\% significance levels 930 against red noise. Pale regions denote the cone of influence (COI) where edge effects might distort 931 the results. 

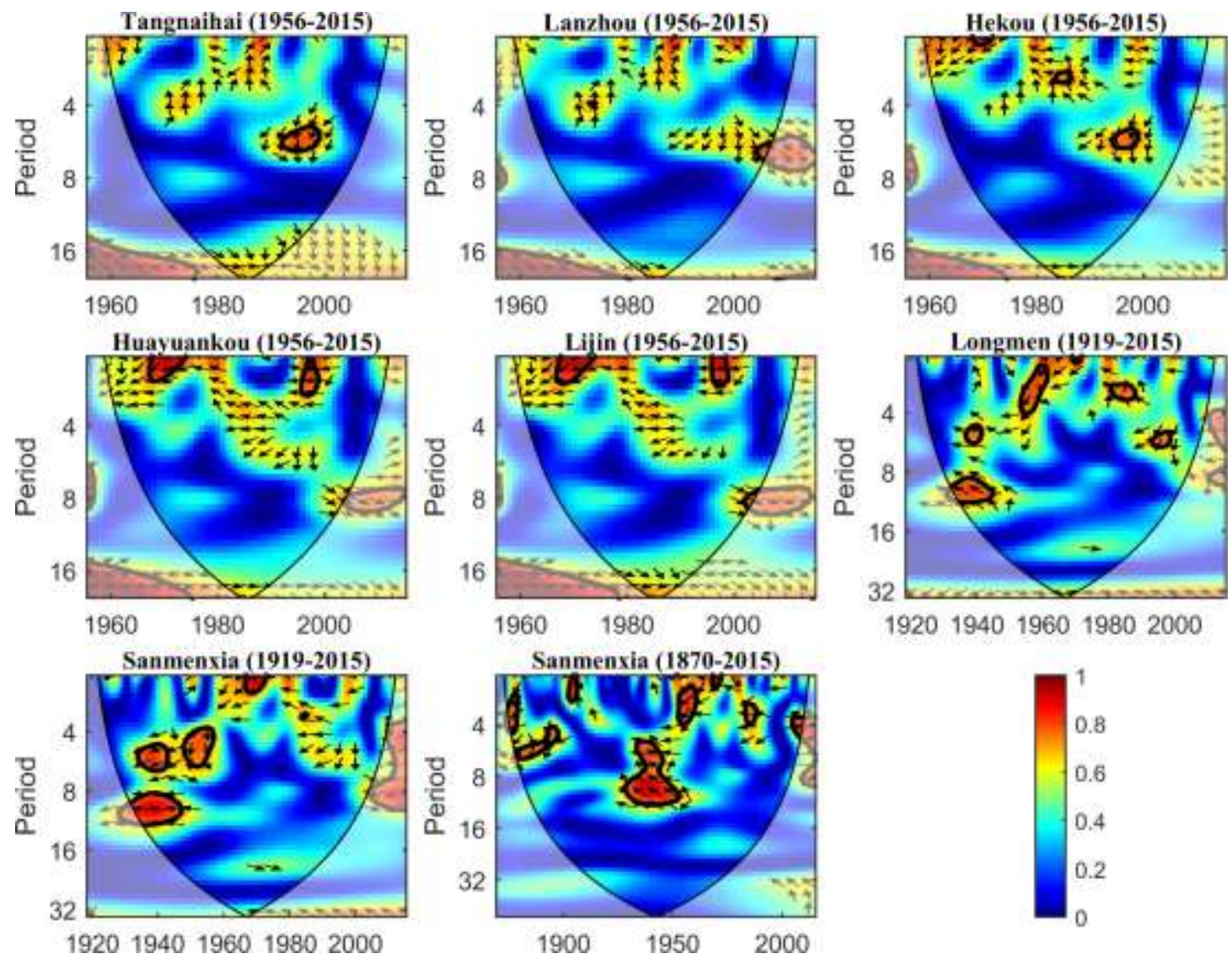

Figure 6. Wavelet transform coherence for Niño 3.4 and natural streamflow. Thick contours denote $5 \%$ significance levels against red noise. Pale regions denote the cone of influence (COI) where edge effects might distort the results. Small arrows denote the relative phase relationship (in-phase, arrows point right; anti-phase, arrows point left). 

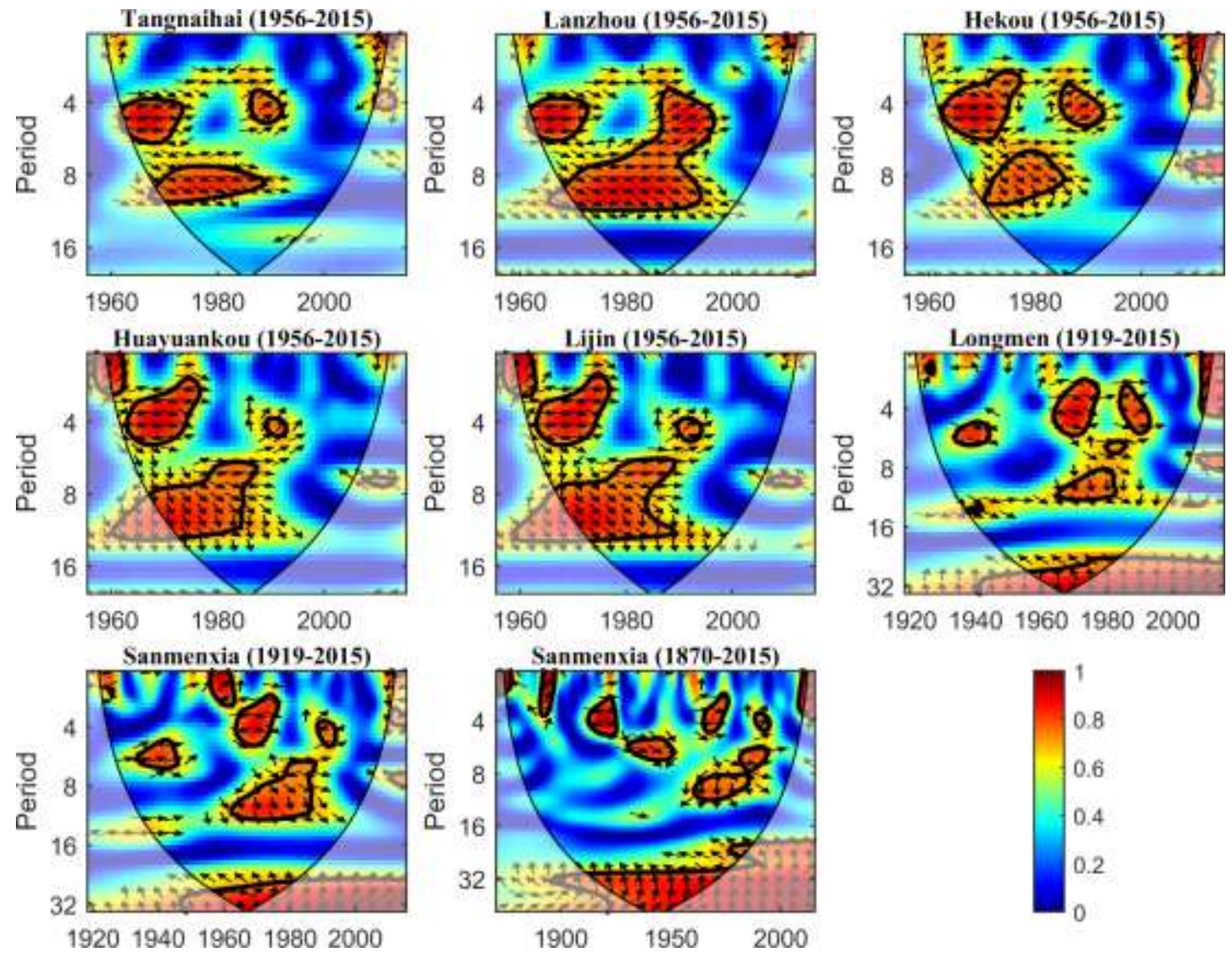

942 Figure 4. Wavelet transform coherence for the AO and natural and reconstructed streamflow.

943 Thick contours denote 5\% significance levels against red noise. Pale regions denote the cone of

944 influence (COI) where edge effects might distort the results. Small arrows denote the relative 945 phase relationship (in-phase, arrows point right; anti-phase, arrows point left). 

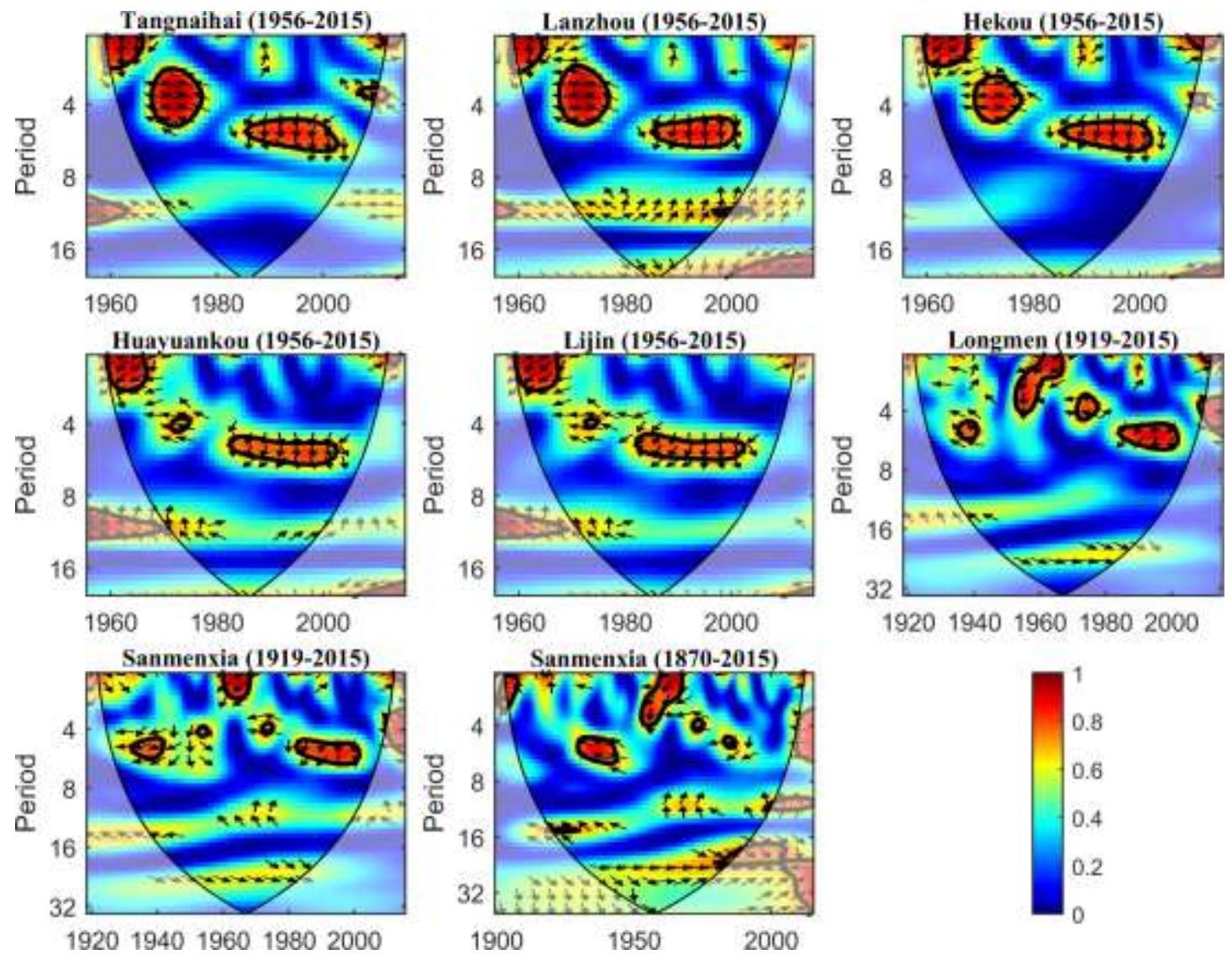

949 Figure 7. Wavelet transform coherence for the PDO and natural and reconstructed streamflow.

950 Thick contours denote 5\% significance levels against red noise. Pale regions denote the cone of

951 influence (COI) where edge effects might distort the results. Small arrows denote the relative 952 phase relationship (in-phase, arrows point right; anti-phase, arrows point left). 

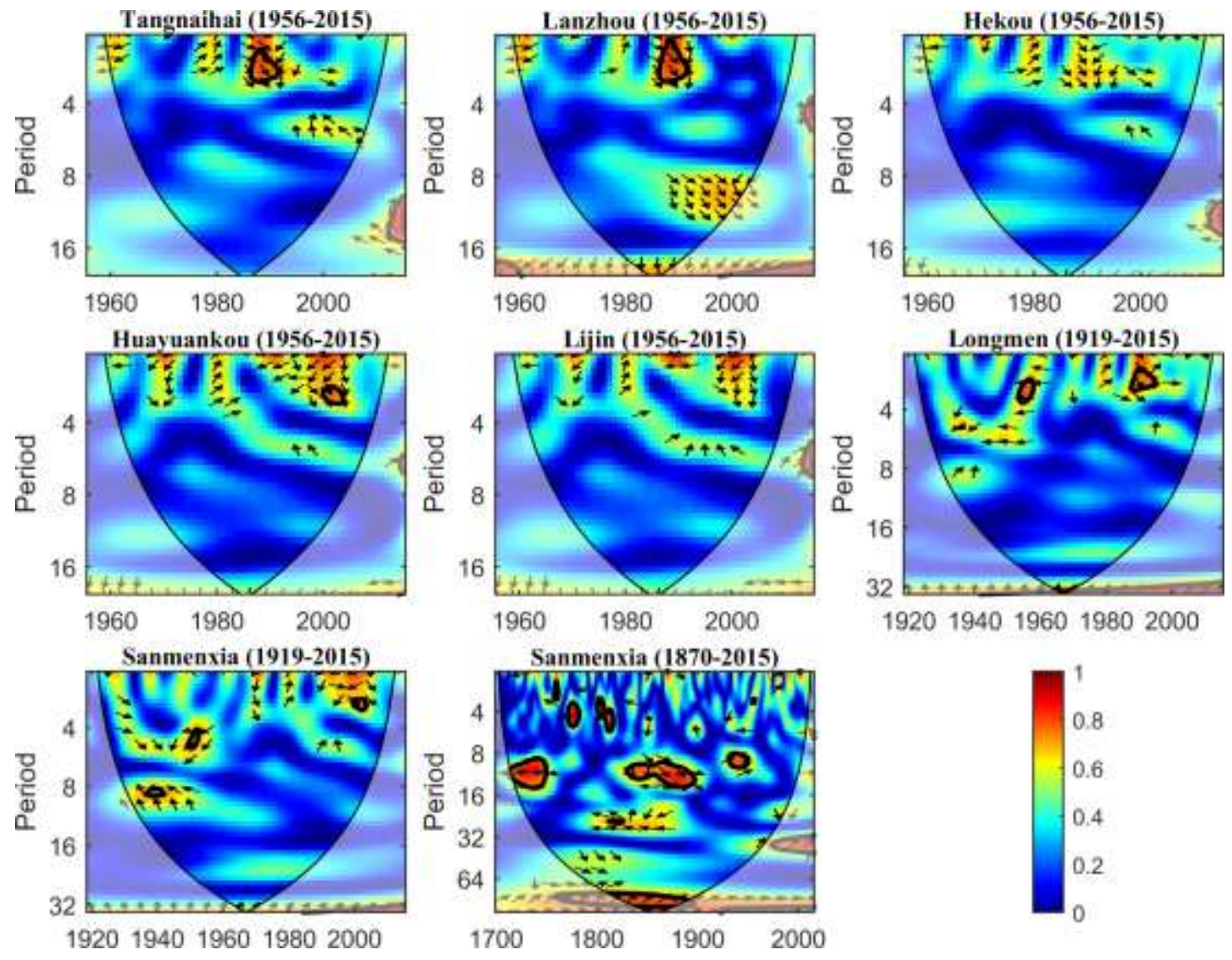

956 Figure 8. Wavelet transform coherence for sunspot number and natural and reconstructed

957 streamflow. Thick contours denote 5\% significance levels against red noise. Pale regions denote

958 the cone of influence (COI) where edge effects might distort the results. Small arrows denote the

959 relative phase relationship (in-phase, arrows point right; anti-phase, arrows point left). 

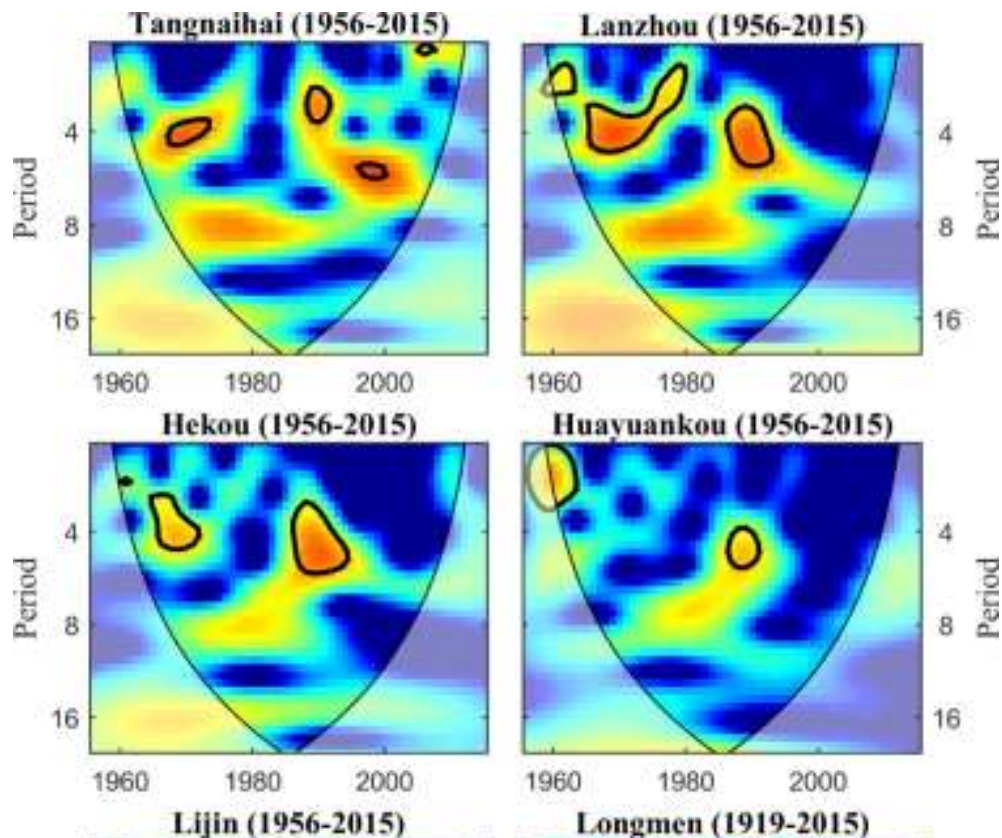

Huayuankou (1956-2015)
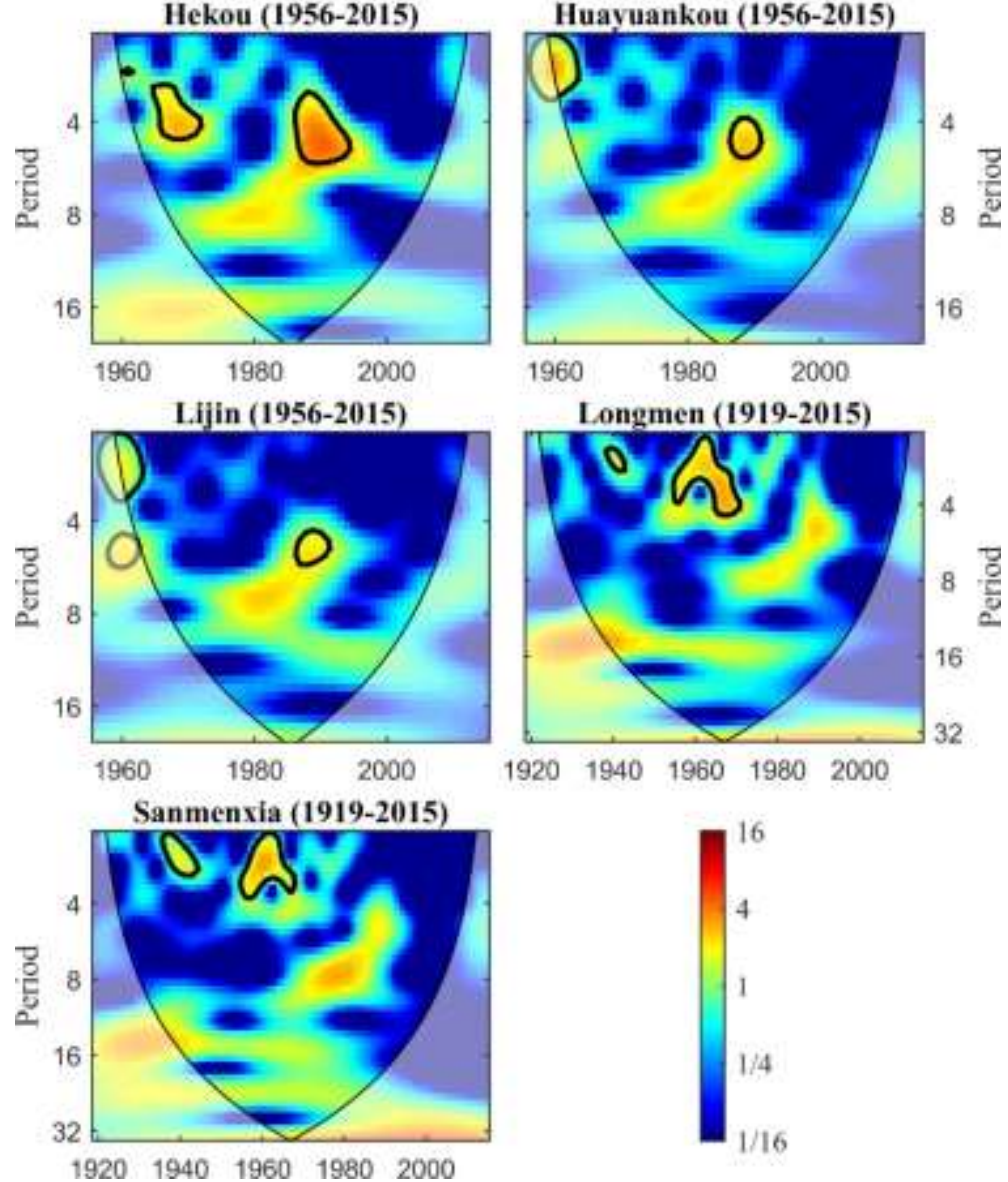

Figure S1. Continuous wavelet transform for the 1956 - 2015 observed time series (Tangnaihai,

964 Lanzhou, Hekou, Huayuankou, Lijin) and the 1919 - 2015 observed time series (Longmen,

965 Sanmenxia). Thick contours denote 5\% significance levels against red noise. Pale regions denote the cone of influence (COI) where edge effects might distort the results. 

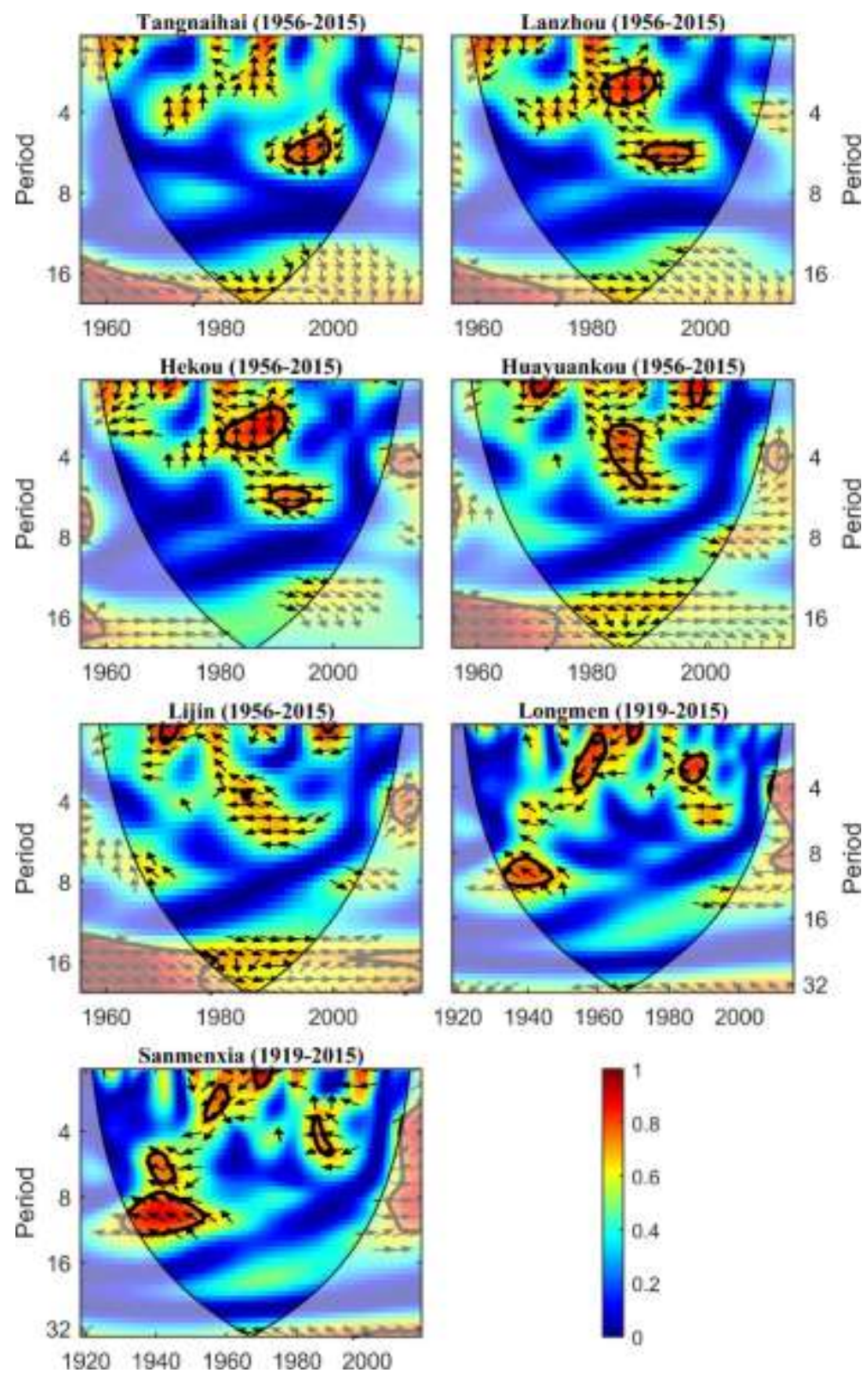

970 Figure S2. Wavelet transform coherence for Niño 3.4 and observed streamflow. Thick contours

971 denote 5\% significance levels against red noise. Pale regions denote the cone of influence (COI)

972 where edge effects might distort the results. Small arrows denote the relative phase relationship

973 (in-phase, arrows point right; anti-phase, arrows point left). 

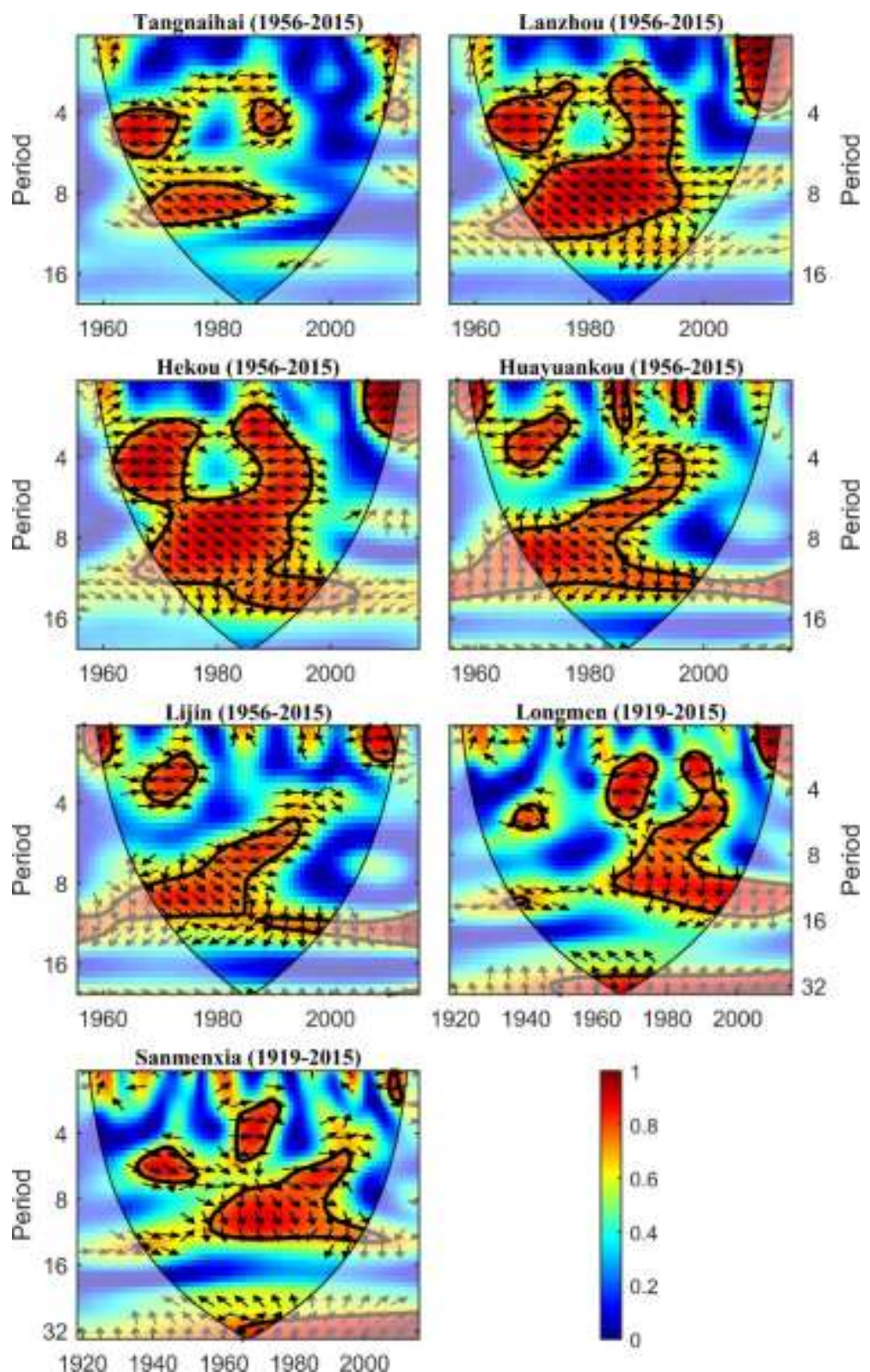

977 Figure S3. Wavelet transform coherence for AO and observed streamflow. Thick contours denote

$9785 \%$ significance levels against red noise. Pale regions denote the cone of influence (COI) where

979 edge effects might distort the results. Small arrows denote the relative phase relationship (in-phase,

980 arrows point right; anti-phase, arrows point left). 

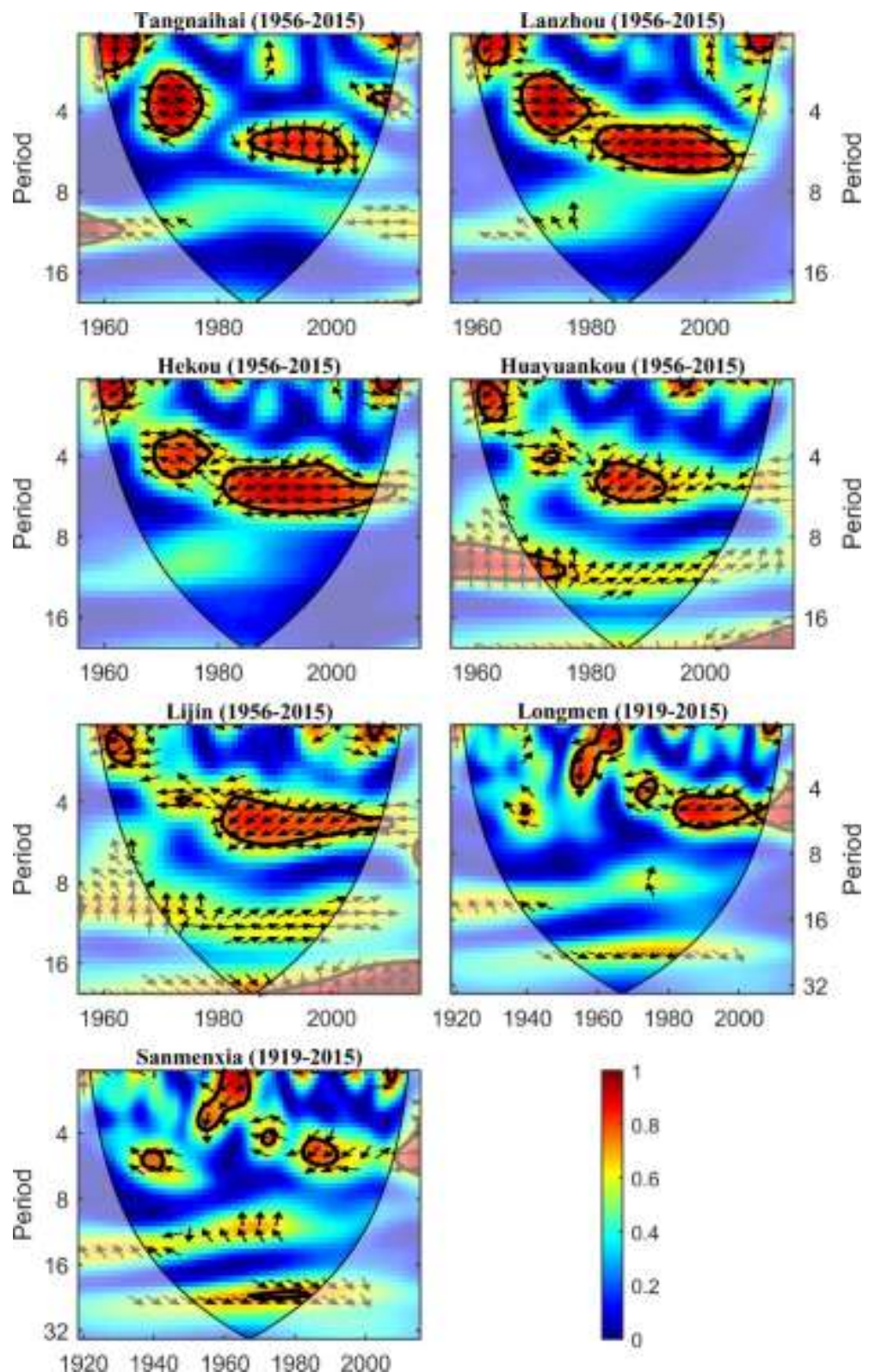

Figure S4. Wavelet transform coherence for PDO and observed streamflow. Thick contours denote $5 \%$ significance levels against red noise. Pale regions denote the cone of influence (COI) where edge effects might distort the results. Small arrows denote the relative phase relationship (in-phase, arrows point right; anti-phase, arrows point left). 

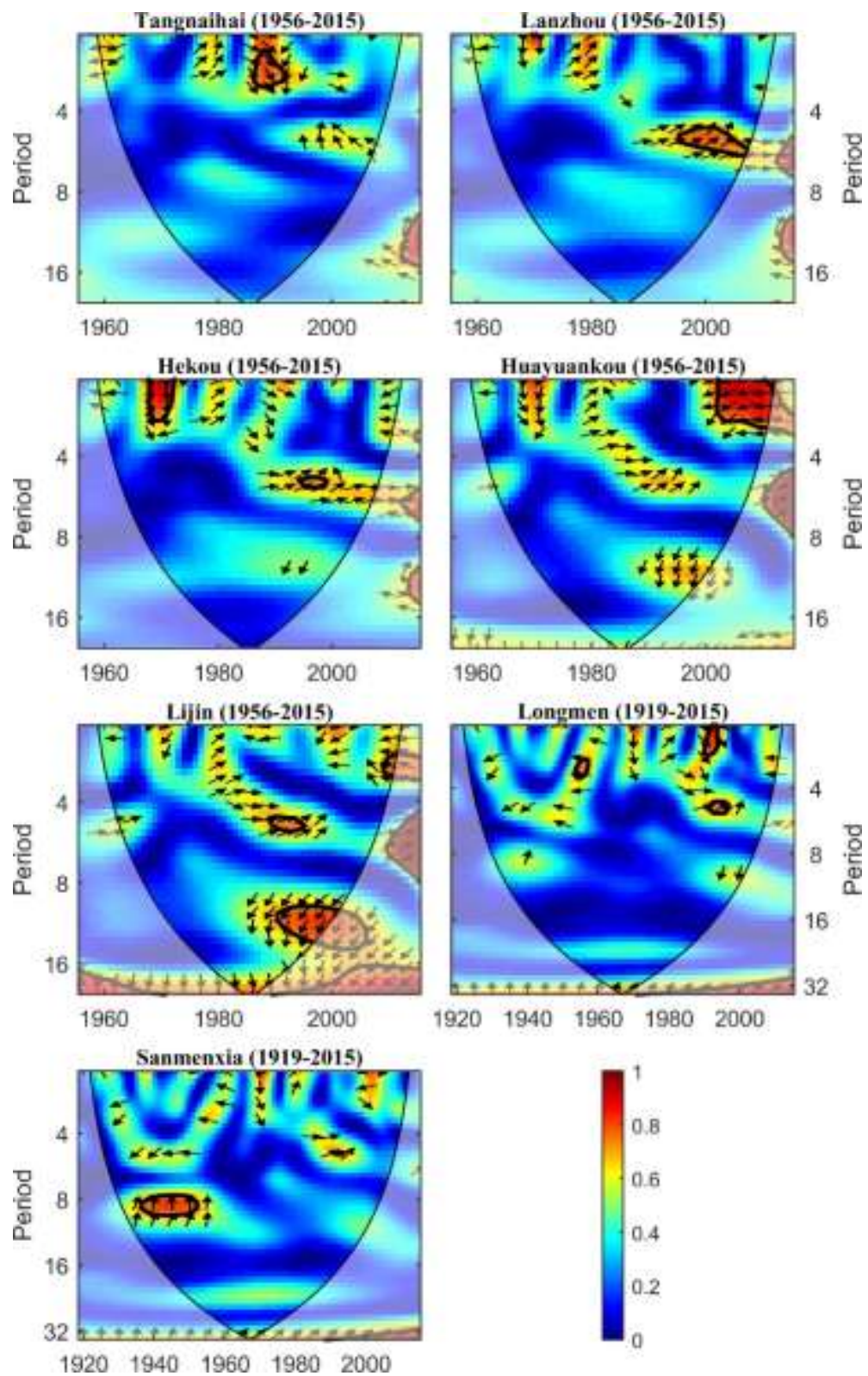

Figure S5. Wavelet transform coherence for sunspots and observed streamflow. Thick contours

992 denote 5\% significance levels against red noise. Pale regions denote the cone of influence (COI)

993 where edge effects might distort the results. Small arrows denote the relative phase relationship

994 (in-phase, arrows point right; anti-phase, arrows point left). 